\title{
Zinc Tellurite Glass System Incorporated with Erbium Oxide and Silver Oxide as Ultra-Broad $(S+C+L)$ Bands Optical Communication
}

S. N. Nazrin ( $\sim$ nazirulnazrin@ymail.com )

Princess Nourah bint Abdulrahman University

\section{K. Halimah}

University Putra Malaysia

\section{S. P. Yee}

University of Malaya

Imed Boukhris

King Khalid University

Imen Kebaili

King Khalid University

\section{Research Article}

Keywords: Tellurite glass, Ag20, photoluminescence, McCumber theory, Judd-Ofelt analysis, white light application

Posted Date: January 31st, 2022

DOI: https://doi.org/10.21203/rs.3.rs-1301269/v1

License: (c) (1) This work is licensed under a Creative Commons Attribution 4.0 International License. Read Full License 
Zinc Tellurite Glass System Incorporated with Erbium Oxide and Silver Oxide as Ultra-broad $(\mathrm{S}+\mathrm{C}+\mathrm{L})$ Bands Optical Communication

\author{
S. N. Nazrin ${ }^{1 *}$, M. K. Halimah', S. P. Yee ${ }^{3}$, Z.A. Imed Boukhris ${ }^{4,5}$, Imen Kebaili ${ }^{4,5}$ \\ ${ }^{1}$ Department of Physics, College of science, Princess Nourah bint Abdulrahman University, P.O. \\ Box 84428, Riyadh 11671, Saudi Arabia \\ ${ }^{2}$ Department of Physics, Faculty of Science, University Putra Malaysia, Serdang 43400, \\ Selangor, Malaysia \\ ${ }^{3}$ Faculty of Engineering, University of Malaya, Kuala Lumpur, Malaysia \\ ${ }^{4}$ Department of Physics, Faculty of Science, King Khalid University; P.O. Box 9004, Abha, \\ Saudi Arabia; \\ ${ }^{5}$ Laboratoire de Physique Appliquee, Groupe des Materiaux Luminescents, Universite de Sfax, \\ Faculte des Sciences de Sfax, BP 1171, 3000 Sfax, Tunisia. \\ Correspondence should be addressed to S. N. Nazrin; \\ *nazirulnazrin@ymail.com
}

\begin{abstract}
Melt-quenching method was used to synthesize a series of zinc tellurite glasses doped with erbium oxide and silver oxide. At room temperature, X-ray diffraction (XRD) and density measurement were implemented to characterize the prepared glass samples. The amorphous nature of the glass samples is proven from the XRD spectra obtained in this work. The density of the glass showed an increment trend from 4.4673 to $4.9705 \mathrm{~g} / \mathrm{cm}^{3}$ when adding more silver oxide, which can prove that the glass strength is higher. For photoluminescence analysis, blue, green and red emissions were found in the glass series under $375 \mathrm{~nm}$ excitation wavelength. According to McCumber theory, higher emission cross-section and higher FWHM are efficient for both broadband amplifier and laser application. More extensive and flatter gain with a maximum gain difference has covered both $\mathrm{C}$ and $\mathrm{L}$ bands for optical communication, providing a few channels in the wavelength division multiplex network (WDM). The high efficiency of optical amplification is justified with a higher gain figure of merit and larger gain bandwidth. According to McCumber's theory, all the results proved that 0.03 molar fraction of silver oxide is the most optimum concentration to be applied in the optical application. In Judd-Ofelt analysis, spectroscopic quality factor and shorter lifetime is a crucial parameter for obtaining intense laser transition, strong emission probabilities and encouraging the laser optical transition, which was successfully attained in all glass samples. The present glass system is also applicable for white light application since the standard equal energy point from all glass samples were located near the center of the CIE diagram $(0.33,0.33)$. In the meantime, higher values of CCT range from 6761 to $6937 \mathrm{~K}$ produce light with a better image as compared to lower CCT. Higher CCT is commercially used in LCD (liquid crystal display) and CRT (cathode ray tube) screens. The colour purity is a parameter for better white LED application, whereas low colour purity is for pure white light emission. Therefore, lower colour purity was found around 10.7 around $18.8 \%$ in all glass samples.
\end{abstract}


Keywords: Tellurite glass, $\mathrm{Ag}_{2} \mathrm{O}$, photoluminescence, McCumber theory, Judd-Ofelt analysis, white light application

\section{Introduction}

Glass has been expansively employed in optical applications especially in fiber optics, optical sensors, laser glass and optical lens. Recently, there has been a desirable passion in the study of fiber optics for photonics applications especially in optical telecommunication and for highbandwidth data transfer. Research on silicate-based glass has been widely administered as optical fiber host materials due to its exceptional glass stability, chemical durability and unique optical properties. Nonetheless, the boundless investigation of optical fiber applications leads the researchers to question the advancement of host materials for fiber optics.

McLaughlin et al. (2000) [1] presented the structure of telluride glass by using the consolidation of NMR, neutron diffraction and X-ray diffraction as depicted in Figure 1. It was reported that tellurite crystals, $\mathrm{TeO} 2$ consists of two-isomorphs, paratellurite ( $\alpha$-form) and tellurite ( $\beta$-form). In addition, both tellurite structures have formed an interconnected network of four coordinate tellurium with four bridging oxygen. Their structural unit is known as $\mathrm{TeO}_{4}$ sphenoid, or a distorted $\mathrm{TeO}_{4}$ bipyramid. In the same year, Blanchandin et al. (2000) [2] explained that $\alpha-\mathrm{TeO}_{2}$ structure, $\mathrm{TeO}_{4}$ units comprise of a three-dimensional network by sharing corners, whereas $\beta$ $\mathrm{TeO}_{2}$ structure comprises of a two-dimensional network by sharing corners and edges as illustrated in Figure 2.

Zinc oxide $(\mathrm{ZnO})$ is widely known to enhance mechanical strength and chemical endurance and lower the thermal expansion of the glass system. Salim and other co-workers in 2001 [3] discovered that zinc oxide changes the coordination of tellurite oxide from $\mathrm{TeO} 4$ (trigonal bipyramidal) to $\mathrm{TeO} 3+1$ polyhedron and $\mathrm{TeO} 3$ (trigonal pyramidal) in the tellurite-based glass. $\mathrm{TeO} 4$ (trigonal bipyramidal) consist of a lone pair that can reduce the free movement of its structure during the heating and cooling process. The development of new structural units of $\mathrm{TeO} 4$ is profitable to the tellurite glass formation.

Erbium oxide is one of the rare earth materials that had been used widely in optical and photonic applications. Extensive work is executed to study the inclusion of erbium oxide into the new laser amplifiers. Halimah et al. (2010) demonstrated how the inclusion of $\mathrm{Er}^{3+}$ allows the recognition of laser amplifiers with exceptional performance compared to other laser amplifiers.

On the other hand, silver oxide, along with copper and gold oxide, are among the oxides that can encourage and improve the optical properties of glass material. Halimah et al. (2010) [4] reported that silver oxide is capable of altering the borotellurite glass network by modifying the structural units of the borate network from $\left(\mathrm{BO}_{3}\right)$ to $\left(\mathrm{BO}_{4}\right)$ and tellurite network from $\left(\mathrm{TeO}_{4}\right)$ to $\left(\mathrm{TeO}_{3}\right)$.

Although many researchers have done on the fabrication and characterization of zinc tellurite glasses, there is still no reported work as to encounter on doping the glass system with erbium oxide and silver oxide with a variety of concentration. Surplus, the studies on the optical part such as photoluminescence, McCumber theory, Judd-Ofelt and CIE analysis also have never 
been reported as well. For that reason, a selected glass system from 0.01 to 0.05 molar fraction of silver oxide was investigated and characterized in the aspect of optical properties.

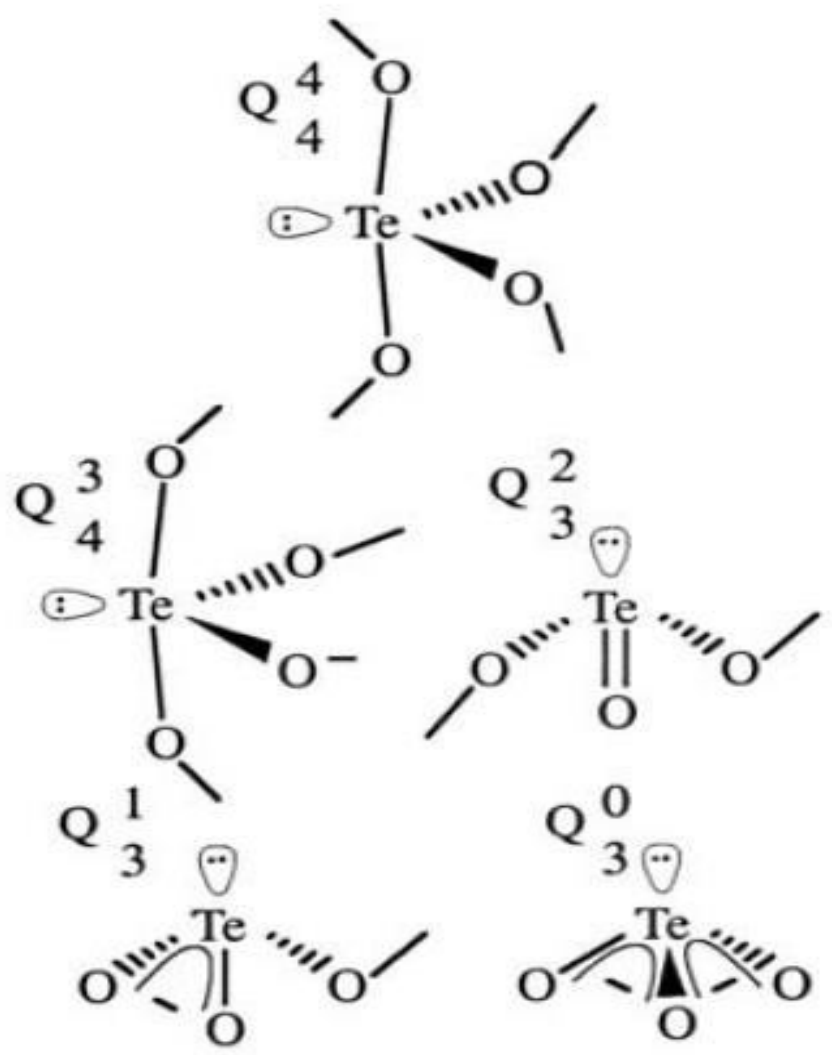

Figure 1: Structure of telluride glass by using the consolidation of NMR, neutron diffraction and X-ray diffraction [1] 


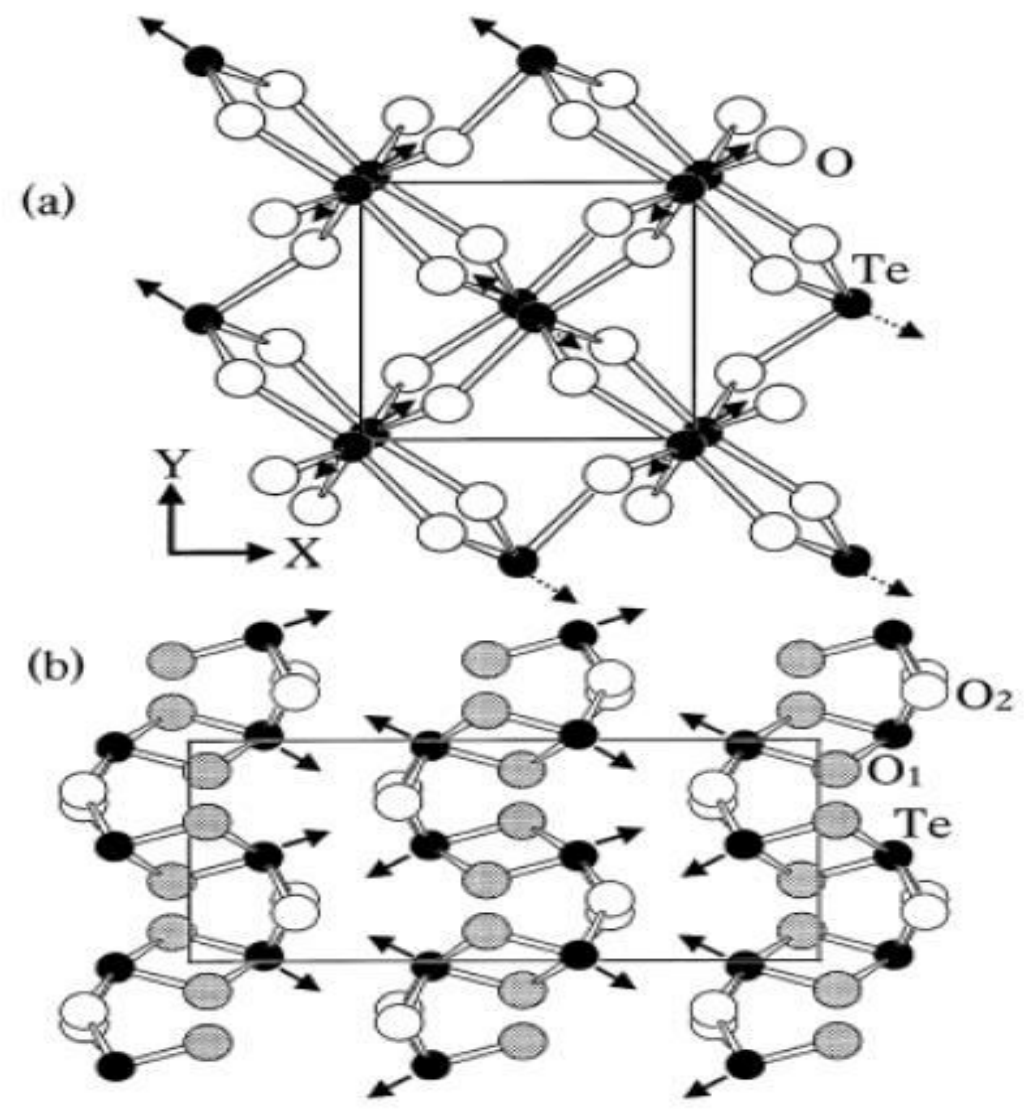

Figure 2: (a) $\alpha-\mathrm{TeO}_{2}$ structure, $\mathrm{TeO}_{4}$ units comprise of a three-dimensional network by sharing and (b) $\beta-\mathrm{TeO}_{2}$ structure comprise of a two-dimensional network by sharing corners and edges [5]

\section{Apparatus, Materials and Methodology}

A series of glass samples were formulated through the melt quenching method. Powder form tellurium (IV) oxide, $\mathrm{TeO}_{4}$ (99.99\%, Alfa Aesar), zinc oxide, $\mathrm{ZnO}$ (99.99\%, Alfa Aesar), erbium (III) oxide, $\mathrm{Er}_{2} \mathrm{O}_{3}$ (99.99\%, Alfa Aesar) and silver (I) oxide, $\mathrm{Ag}_{2} \mathrm{O}$ (99.99\%, Alfa Aesar) were employed in the glass formulation process.

An amount of $13 \mathrm{~g}$ of chemical powders was weighed by using a digital weighing machine (Mettler Toledo) with an error of $\pm 0.0001 \mathrm{~g}$. The weighed chemical powders were transferred into an alumina crucibles and stirred by using a glass rod for 30 minutes to obtain a homogeneous chemical mixture. After that, the alumina crucible and the chemical mixture were put inside an electrical furnace (Lindberg/Blue M) for a pre-heating process at $400^{\circ} \mathrm{C}$ for one hour. The purpose of the pre-heating process is to remove any water content exist in the chemical mixture [6]. After the preheat is done, the chemical mixture containing crucible was transferred to another electrical furnace (Thermolyne) to undergo the melting process at $900^{\circ} \mathrm{C}$ for two hours. As the chemical powder mixture went through the melting procedure, cylinder stainless steel mould was preheated in the first electrical furnace in order to reduce the possibility of the glass sample to crack due to lower mechanical stress in the glass system as the glass was quenched [7]. The molten was then quickly cast into the mould and was continued with the annealing process in the first furnace at $400^{\circ} \mathrm{C}$ for one hour. 
Annealing process was done to decrease the thermal stress in the glass sample as well as to maintain the glass structure [8]. The furnace was switched off after an hour of annealing process and the glass sample was left to cool to room temperature in the furnace overnight.

\section{Theory}

\section{Photoluminescence}

The luminescence process is a mechanism in which an electron emits photon energy during the relaxation of an electron from the highest energy band to the lowest energy band. Normally the photon energy is absorbed by either host lattice or doped impurities. The photon energy is being emitted by the excited impurities ions which are called as the activator ions. The encouragement of a weak absorption from impurities can be implemented by including other types of impurities which can be called as synthesizers. The synthesizers will absorb the photon energy and transfer the energy to the activator ions. The luminescence materials can emit photon energy at different wavelengths and colors. The type of emission wavelength then relies on the type of impurities compounds. Thus, the color of the emission spectra can be altered by adding the impurities without altering the host lattice. Besides that, the emission spectra by the rare-earth ions impurities are highly subjected to their chemical environment. The illustrated diagram of luminescent material containing an activator and sensitizing ions is shown in Figure 3.

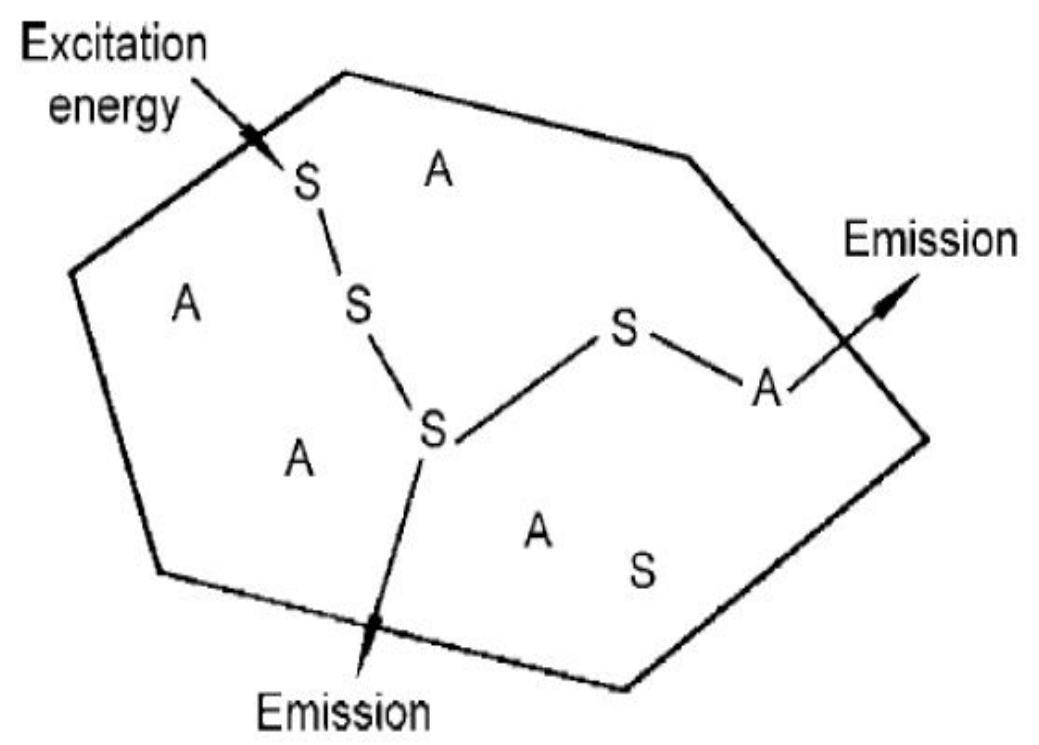

Figure 3: Luminescent material consisting of activator ions, A (showing the desired emission) and sensitizing ions, $\mathrm{S}$ (where the UV excitation can take place) [9]

The emission is emitted from the optical centre which consists of ions or molecules. The luminescence may produce sharp either emission or broad bands in the visible range of wavelength. Various chemical bonding at the ground state and the excited state will create broad emission peaks. Moreover, broad emission bands can be found in most of the optical transitions in the d-orbital of transition metal ions ( $d \rightarrow d$ transitions), between $5 \mathrm{~d}$ and $4 \mathrm{f}$ (rare-earth) orbitals ( $\mathrm{d} \rightarrow \mathrm{f}$ transitions) and ions that possess a lone pair. Meanwhile, the identical chemical bond that happened at the ground state and excited state caused the formation of sharp emission 
bands. The $\mathrm{f} \rightarrow \mathrm{f}$ transition in rare-earth ions is also associated with the same reason. The emission produced by an electron describes the dependency between the optical properties and the chemical bonding. Therefore, the type of chemical bonding (ionic or covalent) and the symmetry of the local environment around the ions are essential factors in the emission mechanism.

The emission process may occur in radiative/non-radiative relaxation, cross-relaxation, and energy transfer. The transfer of energy commonly occurs with synthesizers ions to enhance the weak emission band from the activator ions. In this case, the energy from the synthesizer's ions will be transferred to the activator ions to increase the emission band. At the same time, the host lattice can act as a synthesizer that transfers the energy from the host lattice to the activator ions. The energy transfer process between the synthesizer ions and activator ions can be written as:

$$
S^{*}+A \rightarrow A^{*}+S
$$

The energy transfer process originated from the electrostatic and exchange interaction. The electrostatic interaction can correlate to the coulombic interactions between ions and the exchange interaction caused by the double electron substitution reaction. The energy transfer that is attributed to the coulombic interaction does not need physical interaction between ions. The coulombic interaction occurs when the excited synthesizer electron induces the dipole oscillation on the activator ion. Meanwhile, the exchange transfer requires a physical contact in which the electronic charge distribution is overlapped. The illustrated explanation of the energy transfer process is shown in Figure 4.

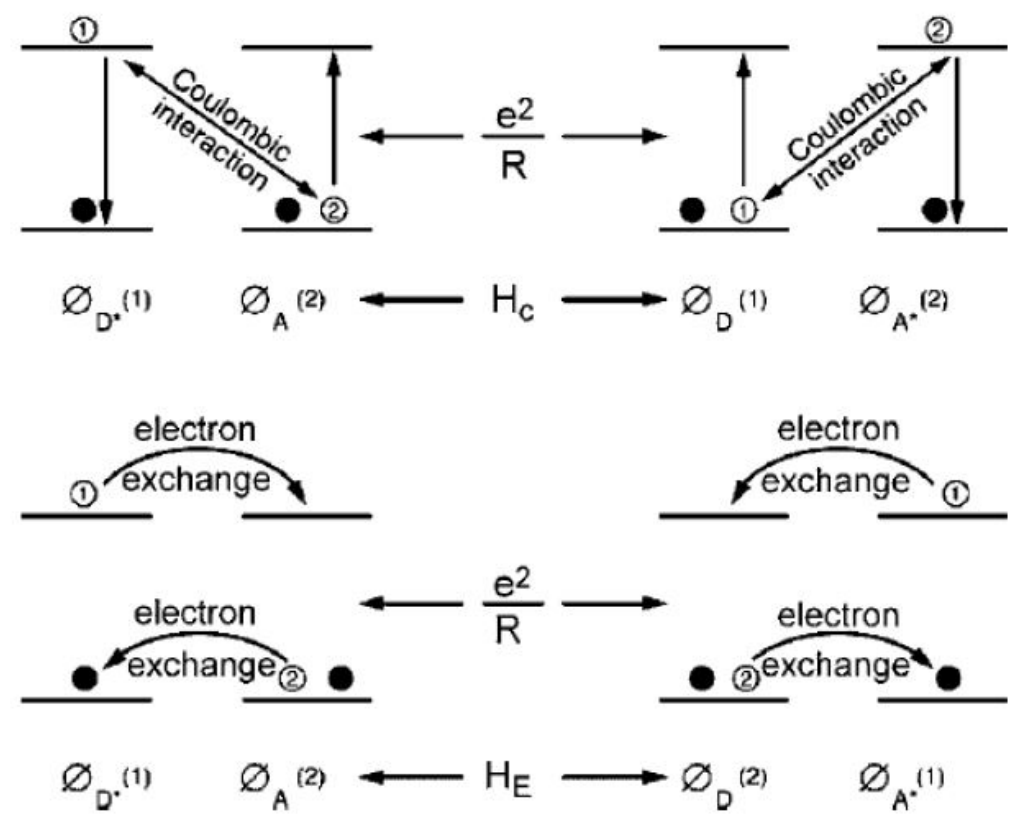

Figure 4: Visualization of energy transfer by Coulomb interaction (a) and exchange interaction (b) between two ions [9]

The cross-relaxation process occurs when an excited electron transfers parts of its energy to another ion. The quenching of the emission band is associated with the cross-relaxation process. 
Besides that, the rate of this process is lower at a low concentration of ions. The distance between the excited ions will influence the cross-relaxation process. The two ions will have a low cross-relaxation rate at a significant distance but a high cross-relaxation rate at a very close distance. Therefore, at very high concentrations of synthesizer ions, the quenching of the emission band may occur.

\section{McCumber theory}

\section{Absorption and emission cross-section}

The purpose of implementing the McCumber theory is to identify the emission cross-section in both transition metal and rare earth ions doped glasses [10]. The theory determines the emission cross-section information from the absorption data of UV-Vis analysis [11]. Due to great difficulty in figuring out the cross-sections of emission and absorption, the measurement using the absorption data is much easier and more efficient as the data for both absorption and emission cross-sections are in accord with the experimental one [12].

The energy is attained in the form of narrow energy with the width of the individual Stark level. However, the condition must consider the thermal distribution of the population where the time taken for the ground state and excited state to reach thermal equilibrium is shorter than the radiative lifetime of the excited level [13].

The absorption cross-section $\sigma_{a b}$ is determined from the absorption coefficient, $\alpha$ and sample thickness, $\mathrm{d}$ as:

$$
\sigma_{a b}(\lambda)=\frac{\alpha(\lambda)}{N}
$$

The emission cross-section $\left(\sigma_{e m}\right)$ is then obtained using the absorption coefficient which had been reported by [14] as:

$$
\sigma_{e m}=\sigma_{b} \exp \left(\frac{\varepsilon-h v}{k T}\right)
$$

where $N$ is the ion concentration, $k$ is the Boltzmann constant, $\varepsilon$ is the net-free energy required to excite an ion from the ground state to the first excitation state, $v$ is the frequency, and $T$ is the absolute temperature $[12,15]$

\section{Gain coefficient}

At a population inversion coefficient value, p, the gain coefficient $g(\lambda)$ is attained for a signal wavelength, $\lambda$ as proposed by $[16,17]$ :

$$
g(\lambda)=\sigma_{e m}(\lambda) \mathrm{Np}-\sigma_{a b}(\lambda) \mathrm{N}(1-\mathrm{p})
$$

\section{Full width half maximum (FWHM), gain bandwidth and gain figure of merit}

The full width at half maximum (FWHM) is an interpretation of the range of a function given by the variation between the two extreme values of the independent variable at which the dependent variable is equivalent to half of its highest value. It also can be explained as the width of a spectrum curve measured between those points on the $y$-axis, which are half the maximum amplitude. The FWHM can be found by employing Origin 6.0. The importance of this parameter is to determine another parameter which is the gain bandwidth [18]. The equation used to obtain the gain bandwidth can be expressed as follows: 
whereas gain FOM can be noted as:

$$
\text { Gain bandwidth }=\sigma_{\text {em }} x \text { FWHM }
$$

$$
\text { Gain } F O M=\sigma_{e m} x \tau_{r}
$$

Meanwhile, radiative lifetime is a lifetime of an electronic state in the situation where only radiative process depopulates on particular level.

\section{Judd-Ofelt theory}

The approach of Judd-Ofelt theory $[19,20]$ presents the understanding of transition behaviour between $4 \mathrm{f}-4 \mathrm{f}$ electronic configuration and transition probabilities evaluation, ratio intensity parameters, oscillator strength and branching, oscillator strength and intensity parameters $\left(\Omega_{1}, \Omega_{2}, \Omega_{3}\right)$. Judd-Ofelt theory is a crucial knowledge to identify the spectral properties of erbium ions doped with host glass materials The Judd-Ofelt theory reveals the exact integrated cross-section measurement of absorption over the spectrum of wavelength as well as the transition state of excitation. The experimental oscillator strength for every excitation state transition is expressed as the following relation:

$$
f_{\text {exp }}=\frac{2.303 m c^{2}}{N \pi e^{2}} \int \varepsilon(\sigma) d \sigma
$$

where $N$ is the concentration of $\mathrm{Er}^{3+}$ ions in $\mathrm{cm}^{-1}, \varepsilon(\sigma)$ is the molar absorptivity in $L /$ $(\mathrm{mol} . \mathrm{cm})$ attained from the absorbance data of the glass system. The molar absorptivity, $\varepsilon(\sigma)$ at a provided energy, is calculated from Beer-Lambert Law as expressed below:

$$
\varepsilon(\sigma)=\frac{1}{c l} \log \frac{I_{o}}{I}
$$

where $c$ is the concentration of $E r^{3+}$ ion (mol\%), $l$ is the thickness of the glass sample (cm) and $\log \frac{I_{O}}{I}$ is the optical density (OD). The estimation of the theoretical oscillator strength of an electric dipole transition from (SL)J to ( $\left.\mathrm{S}^{\prime} \mathrm{L}^{\prime}\right) \mathrm{J}$ ' is determined by using Judd-Ofelt theory, as shown by the following expression:

$$
f_{\text {cal }}=\frac{8 \pi^{2}}{3 h(2 J+1)} \frac{\left(n^{2}+2\right)^{2}}{9 n} \sigma \cdot \sum_{\lambda=2,4,6} \Omega_{\lambda}\left|<(S L J)\left\|U^{(\lambda)}\right\|\left(S^{\prime} L^{\prime} J^{\prime}\right)>\right|^{2}
$$

where $h$ is Planck's constant, $c$ is the speed of light, $m$ is the mass of the electron, $n$ is the refractive index, and $\left|U^{(\lambda)}\right|$ is the doubly reduced matrix elements of the unit tensor operator. The Judd-Ofelt parameter is computed by using the least-square fitting procedure which gives the best fit between the experimental and the calculated oscillator strength. Judd-Ofelt theory can determine the line strength, $S_{m}$ from an integrated absorption cross-section by the following expression $[19,20]$ :

$$
S_{m}=\frac{3 \operatorname{ch}\left(2 J^{2}+1\right)}{8 \pi^{3} e^{2} \lambda} n\left(\frac{3}{n^{2}+2}\right)^{2} \int_{\text {manifold }} O D(\lambda) \mathrm{d} \lambda
$$

where $J^{\prime}$ is the total angular momentum of lower state, $\lambda$ is the mean wavelength and $O D(\lambda) \mathrm{d} \lambda$ is the optical density over the range of wavelength. The theoretical expression of electric dipole line strength is given by:

$$
S_{E D}=\sum_{t-2,4,6} \Omega_{t}\left|<f^{n}[S L] J\left\|U^{t}\right\|\left[S^{\prime} L^{\prime}\right] J^{\prime}>\right|^{2}
$$

where $\Omega_{t}$ is the Judd-Ofelt parameters. The reduced matrix element, $\left|U^{(\lambda)}\right|$ can be evaluated in the intermediate-coupling approximation and is invariant of the environment. The Judd-Ofelt 
theory minimizes the square of the difference between $S_{m}$ and $S_{E D}$ with $\Omega_{t}$ as adjustable parameters $[19,20]$.

The Judd-Ofelt parameters $\left(\Omega_{\lambda}, \lambda=2,4,6\right)$ can be utilized to compute the radiative transition probability, $A_{\text {rad }}$, electric dipole transition probability, $A_{\mathrm{ed}}$, magnetic dipole transition probability, $A_{\text {md }}$, fluorescence branching ratio, $\beta$ and radiative lifetime, $\tau_{\text {rad }}$ of $\mathrm{Er}^{3+}$ ions [21]. The radiative transition probability, $A_{\text {rad }}$ (also known as Einstein coefficient for spontaneous emission) for any excited transition state can be expressed by the following relation:

$$
A_{\text {rad }}=\frac{64 \pi^{3} e^{2}}{3 h(2 J+1) \lambda^{3}}\left[n\left(\frac{n^{2}+2}{3}\right)^{2} S_{E D}+n^{3} S_{M D}\right]
$$

The magnetic dipole line strength, $S_{M D}$ is neglected since the excitation bands are principally electric dipole in nature. The fitting quality between $S_{E D}$ and $S_{\text {meas }}$ is shown by the following expression:

$$
\Delta S_{r m s}=\left[(q-p)^{-1} \sum\left(S_{E D}-S_{\text {meas }}\right)^{2}\right]^{1 / 2}
$$

where $q$ is the number of the spectral band analysed and $p$ is the number of JO parameters calculated. The branching ratio, $\beta$ and radiative lifetime, $\tau_{\text {rad }}$ of $\mathrm{Er}^{3+}$ can be calculated by using the following equation:

$$
\begin{gathered}
\beta\left(J \rightarrow J^{\prime}\right)=\frac{A_{\text {rad }}\left(J \rightarrow J^{\prime}\right)}{\left[\sum A_{\text {rad }}\left(J \rightarrow J^{\prime}\right)\right]} \\
\tau_{\text {rad }}=\frac{1}{\left[\sum A_{\text {rad }}\left(J \rightarrow J^{\prime}\right)\right]}
\end{gathered}
$$

Other than that, the bonding parameters of erbium ions and surrounding ligand was described by Hamzah et al., (2019) [22]:

$$
B=\frac{v_{c}}{v_{a}}
$$

where $B$ is called as the nephelauxetic ratio, $v_{c}$ is the wavenumber $\left(\mathrm{cm}^{-1}\right)$ of a particular transition from erbium in the glass and $v_{a}$ is the wavenumber $\left(\mathrm{cm}^{-1}\right)$ of the same transition for the aqua ion. Both $v_{c}$ and $v_{a}$ can be attained from UV-Vis optical absorption spectra of glass and a standard value reported by Yusoff and Sahar, (2015) [23] respectively.

As a consequence, the bonding parameter, $\sigma$ is evaluated from the attained nephelauxetic ratio via the expression made by Yusoff and Sahar, (2015) [23]:

$$
\sigma=\frac{1-B^{\prime}}{B^{\prime}} \times 100 \%
$$

where $B^{\prime}$ is an average nephelauxetic ratio, the metal-ligand is covalent when $\sigma$ is positive and ionic when $\sigma$ is negative. In 2014, Kothari [24] had reported another bonding parameter of $b^{1 / 2}$ in term of $B^{\prime}$ as given by:

$$
b^{1 / 2}=\left[\frac{1-B^{\prime}}{2}\right]^{1 / 2}
$$


A real value of $b^{1 / 2}$ indicates covalent bonding. This parameter is very useful for comparing the bonding study.

The crystal field strength, $D_{q}$ and racah parameters $(R$ and $C$ ) are examples of the ligand field parameters. These parameters can be identified from the optical absorption band position $\left(v_{1}, v_{2}\right.$, $v_{3}$ in $\mathrm{cm}^{-1}$ ) using the relation made by Hassan, (2013) and Yusoff and Sahar, (2015) [23,25]:

$$
\begin{gathered}
10 D_{q}=v_{1} \\
R=\frac{\left(2 v_{1}-v_{2}\right)\left(v_{2}-v_{1}\right)}{27 v_{1}-15 v_{2}} \\
C=\frac{v_{3}-4 R-10 D_{q}}{3}
\end{gathered}
$$

\section{White light theory}

White light is a uniform mixture of all visible light. In daily life, the sunlight is present in the form of white light since the sunlight contains the entire visible spectrum [26]. The pure white light is said to consist of all the colours of the rainbow. Nonetheless, the white light can also be attained from dichromatic, trichromatic or tetrachromatic approaches as shown in Figure 5 [27]. In this work, the white light is formed by employing two emission bands (dichromatic source), which are yellow and blue. At a certain power ratio, these two complementary light sources are required in the formation of white light. It can generate more comfortable and more robust white light from the insertion of more colours [28].

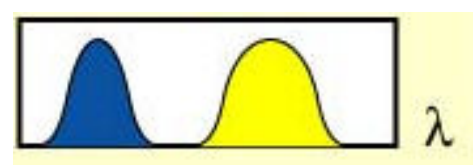

Dichromatic white source

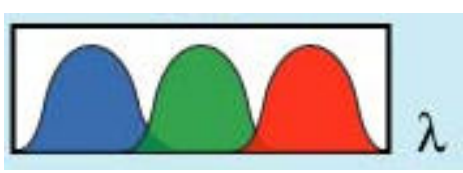

Trichromatic white source

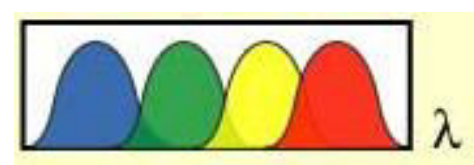

Tetrachromatic white source

Figure 5: Different approaches to the generation of white light [27]

In the formation of white light, the white light emission from the host lattice can be governed by three different methods which include

a) doping a single rare-earth ion,

b) doping of two or more rare-earth ions (excited concurrently) and,

c) co-doping of different ions and controlling the emission through energy transfer processes [29].

Nevertheless, in this research, the white light has been stimulated from the rare earth $\left(\mathrm{Ag}^{2+}\right)$ ions doped glass materials by modifying the glass composition, composition of rare-earth ion and the excitation wavelength. 


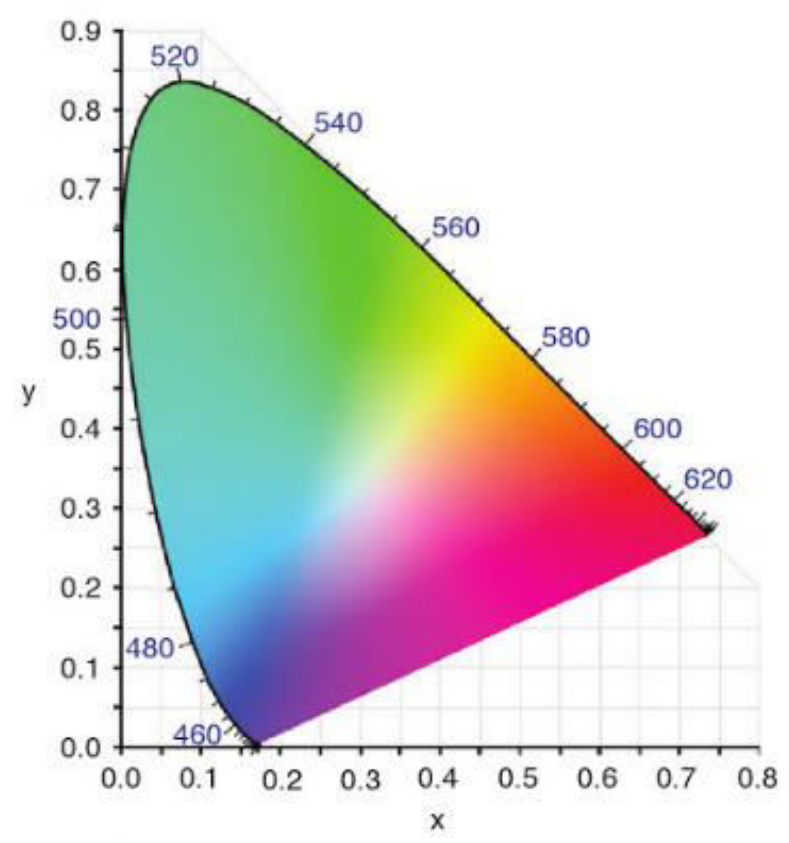

Figure 6: CIE 1931 chromaticity diagram [30]

The generation of white light from the materials by combining the wavelength of yellow and blue lights can be confirmed by using colour chromaticity coordinates. It can be observed from the Commission Internationale de I'éclairage (CIE 1931) chromaticity diagram as displayed in Figure 6. In the diagram mentioned, the lines which represent the blue and yellow region will pass through the white light region. Thus, by knowing the coordinates, the position of white light can be determined [31]. The $\mathrm{x}$ and $\mathrm{y}$ coordinate for standard white light point (equal energy white) is $\mathrm{x}=0.333$ and $\mathrm{y}=0.333$ [32].

\section{Correlated color temperature (CCT)}

The correlated colour temperature (CCT) is a parameter used to characterize the colour of the light. The CCT usually is expressed in degree Kelvin $\left({ }^{\circ} \mathrm{K}\right)$. The CCT value will be used to describe the white light tone produced by the materials. Frequently, when the value of CCT increases, the colour of the light source will shift from the reddish light to the bluish light [33] as shown in Figure 7. From the colour temperature, the light produced can be categorized as warm, neutral or cool light. The categories of light based on the range of the CCT values are presented in Table 1.

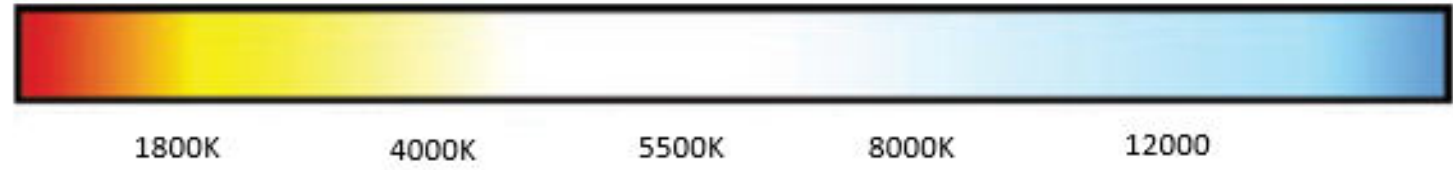

Figure 7: The tone of white light changes according to the temperature [34] 
Table 1: Categories of white light based on CCT value [35]

\begin{tabular}{cc}
\hline Range of CCT $\left({ }^{\circ} \mathrm{K}\right)$ & Effect of light \\
\hline$<3500$ & Warm (Reddish white) \\
3500 to 5000 & Neutral (White) \\
$>5000$ & Cool (Bluish white) \\
\hline
\end{tabular}

The CCT value can be determined by replacing the $\mathrm{x}$ and y color coordinates into the McCamy's approximate formula in the following equation [36]:

$$
C C T=-449 n^{3}+3525 n^{2}-6823 n+5520.33
$$

where $n=(x-0.332) /(y-0.186)$ is the inverse slope line and the values 0.332 and 0.186 is the epicentre ( a point on the chromaticity diagram).

\section{Result and Discussion \\ Photoluminescence spectra analysis}

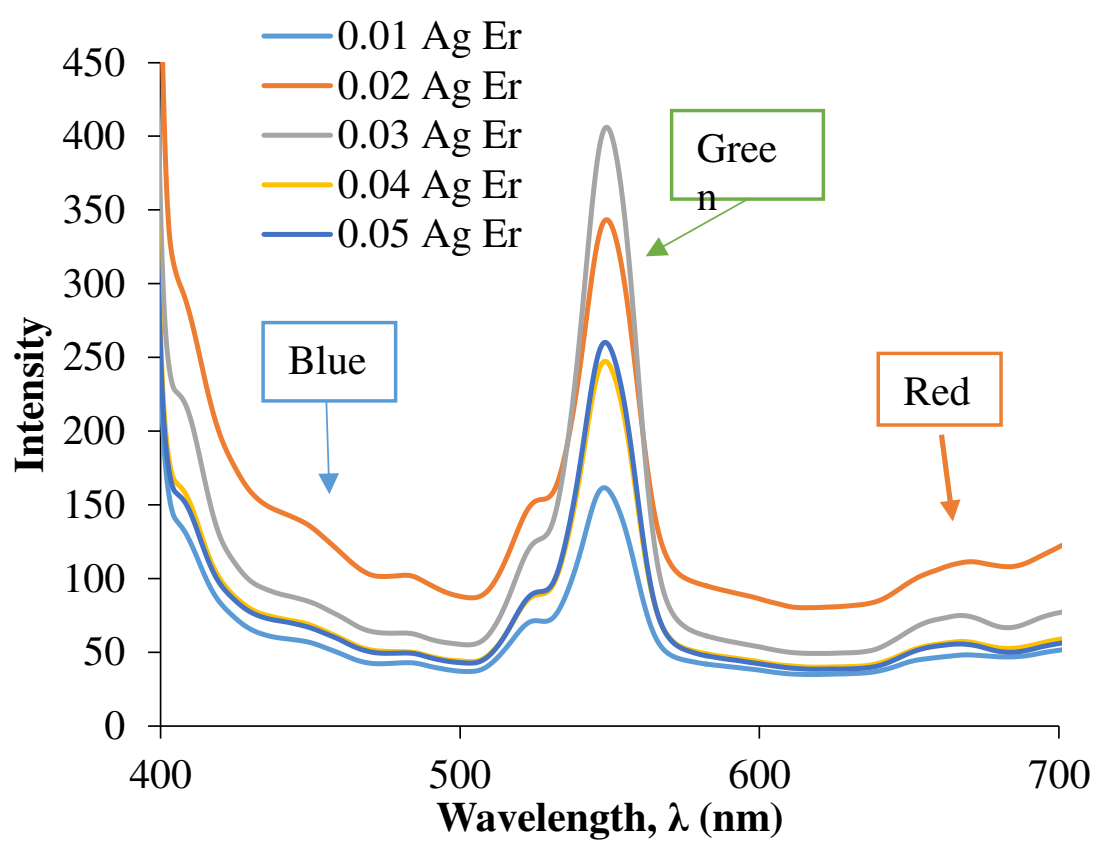

Figure 8: Photoluminescence spectra of silver-doped erbium zinc tellurite glasses

Figure 8 displays the photoluminescence spectra against zinc tellurite glasses doped with erbium oxide and silver oxide under $375 \mathrm{~nm}$ excitation wavelength. Green $(550 \mathrm{~nm})$ and red $(650 \mathrm{~nm})$ emissions are observed in the photoluminescence spectra. The intensity of blue emission can also be observed slightly at the early $400 \mathrm{~nm}$. According to Fang et al., (2007) [37], the observed bands as depicted in the figure can be attributed to the stark splitting effect which can be assigned by low symmetry of the local environment around erbium ions sites. By referring to the photoluminescence figure, the insertion of both erbium and silver ions is affecting the total emission intensity. However, the shape of the emission spectra remains the same. Mahraz et al., (2013) [38] had mentioned that the increment in silver oxide brought a capability to diminish the emission intensities in the visible range. The increment in silver oxide concentration saturated 
the intensity of light, which led to the quenching effect. The quenching effect has been formed by the energy transfer (ET) mechanism from erbium ions to silver ions.

\section{Energy level diagram analysis}

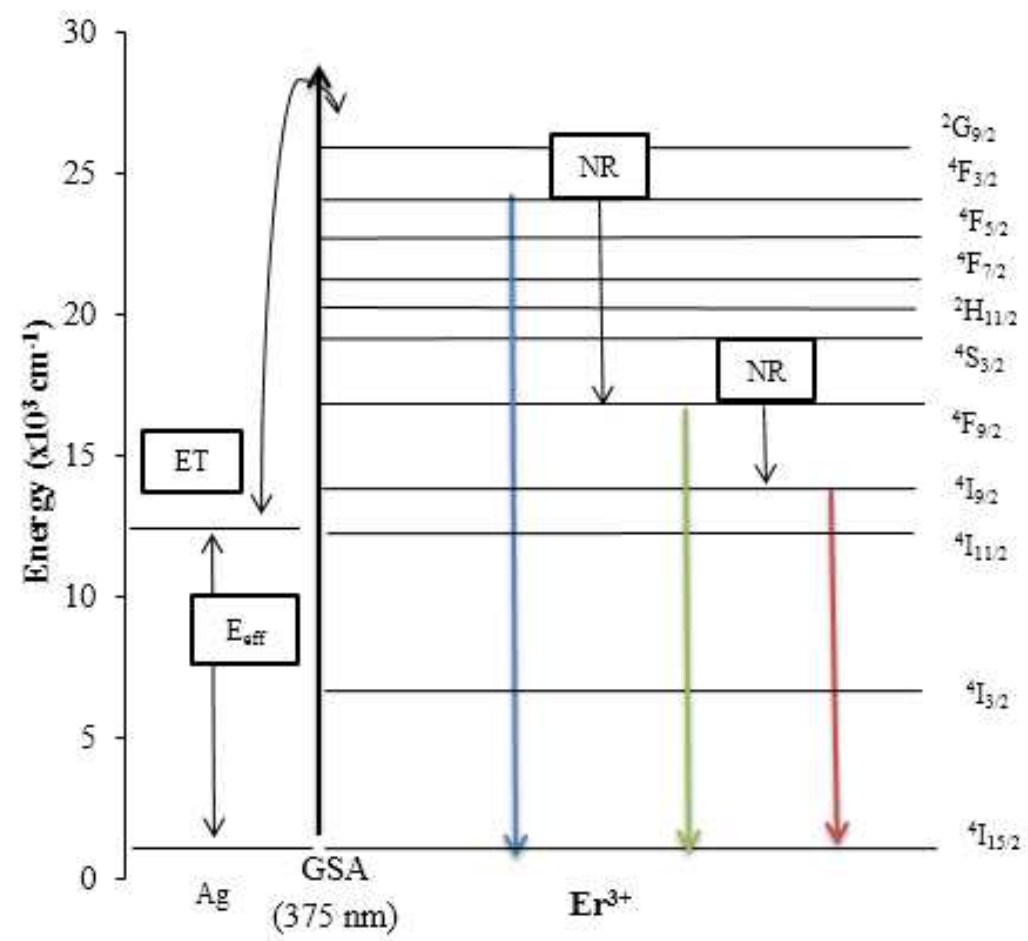

Figure 9: Energy level diagram of silver-doped erbium zinc tellurite glasses for visible emission

Figure 9 displays the energy level diagram of the silver-doped erbium zinc tellurite glass system [38-39]. In 2016, Mahraz and other co-authors [40] had revealed that the excited states at ${ }^{4} \mathrm{~F}_{3 / 2}$, ${ }^{4} \mathrm{~F}_{9 / 2}$ and ${ }^{4} \mathrm{I}_{9 / 2}$ had filled by the cooperative energy transfer (CET) between two erbium ions that exist in the existing glass system. Based on Dousti et al. (2016) [41], the energy transfer from the excited state of erbium ions to the surface of silver ions will result in an unfavourable quenching effect that will be discussed quenching analysis section. 


\section{Quenching effect analysis}

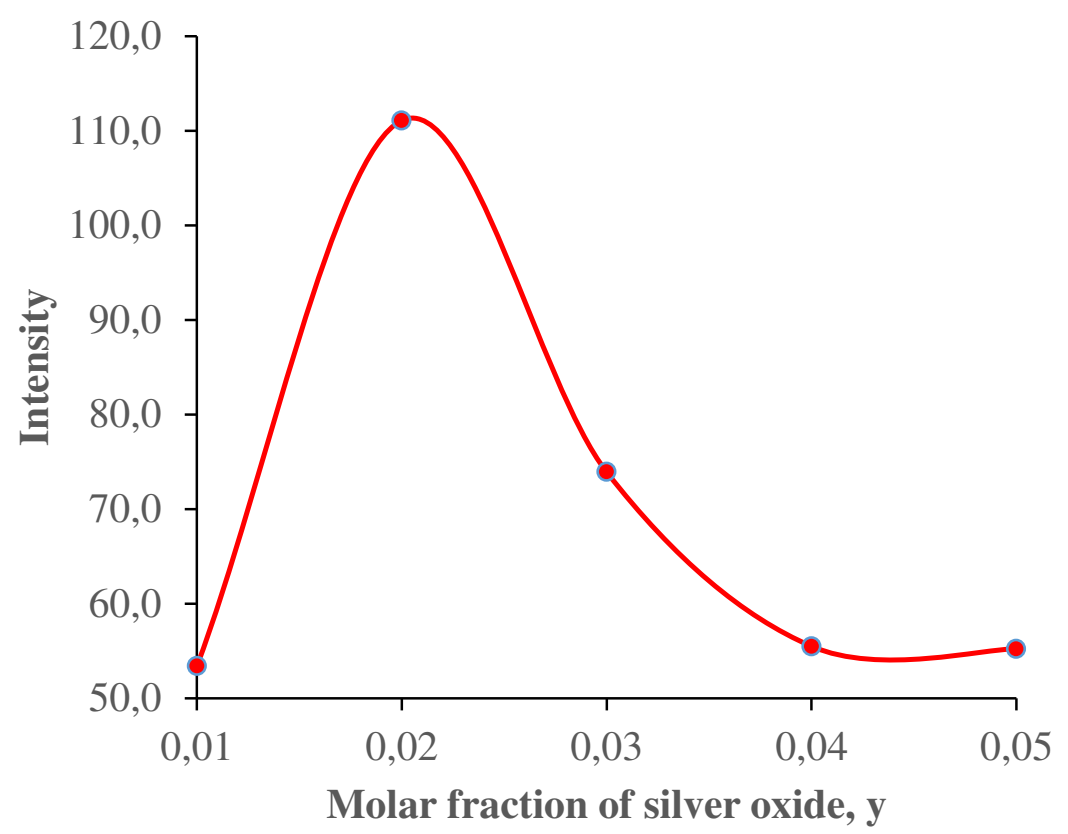

Figure 10: Emission intesities of silver-doped erbium zinc tellurite glasses

What can be observed from the figure is that there is an intermittent decrement of luminescence intensity as the concentration of dopants increases. This phenomenon occurred because of the energy transfer process between the erbium ions (self-quenching or cross-relaxation) [42]. The transfer of energy is a process of converting light to heat via phonon and multi-phonon processes and visible light. Red emissions had reduced significantly in intensity as compared to green and blue emissions. This situation is related to the cross-relaxation process of two neighbouring rareearth ions. The cross relaxational mechanism is more likely to occur at a higher concentration of rare-earth ions when the ion-ion distances are short enough and saturated. This phenomenon (cross-relaxational process) will lead to more quenching effect on the red emission [38]. Other than that, the quenching in luminescence intensity can also be attributed to the non-radiative energy transfer. A high concentration level of dopant is said to speed up the luminescence intensity to decay as well $[22,43]$.

\section{McCumber theory}

\section{Absorption and emission cross-section analysis}

One of the crucial parameters in McCumber's theory is the absorption cross-section. The absorption cross-section can be derived from the absorption spectra (UV-Vis). The emission cross-section is also crucial to determine the potential performance of a laser by relating both absorption and emission cross-sections simultaneously [22,45]. 


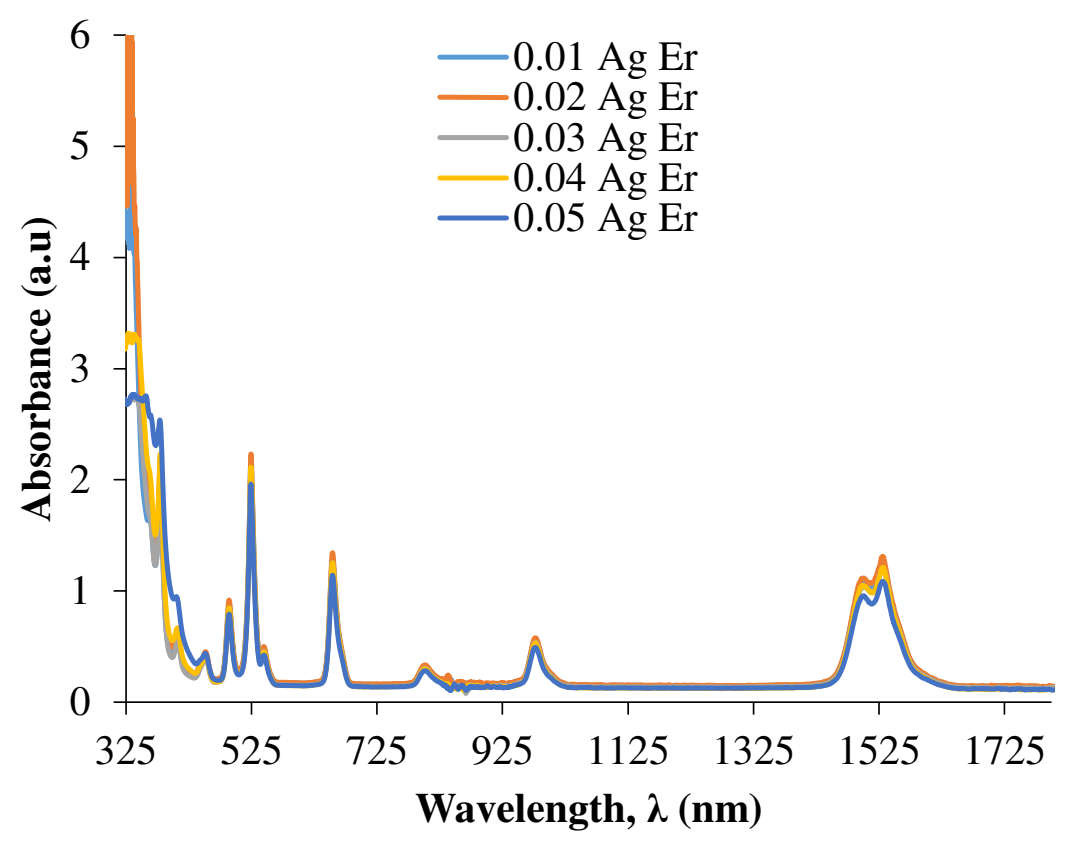

Figure 11: Optical absorbance spectra of silver-doped erbium zinc tellurite glasses

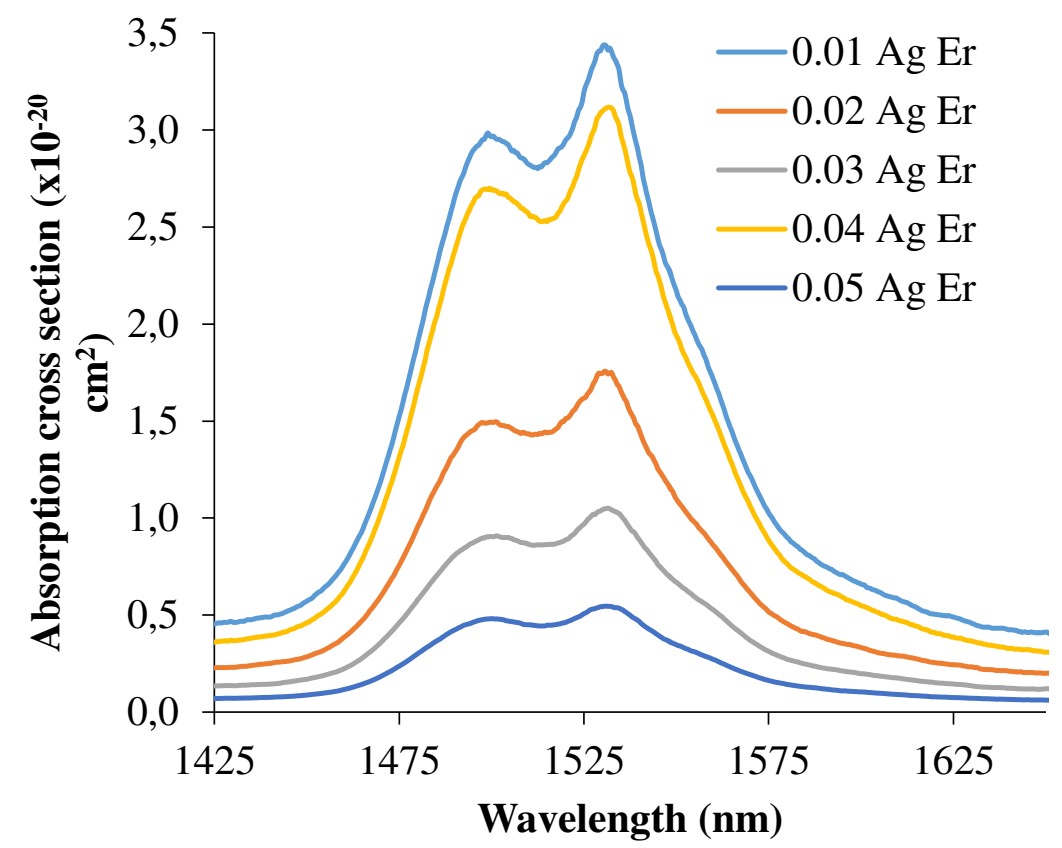

Figure 12: Absorption cross section against wavelength of silver-doped erbium zinc tellurite glasses. 


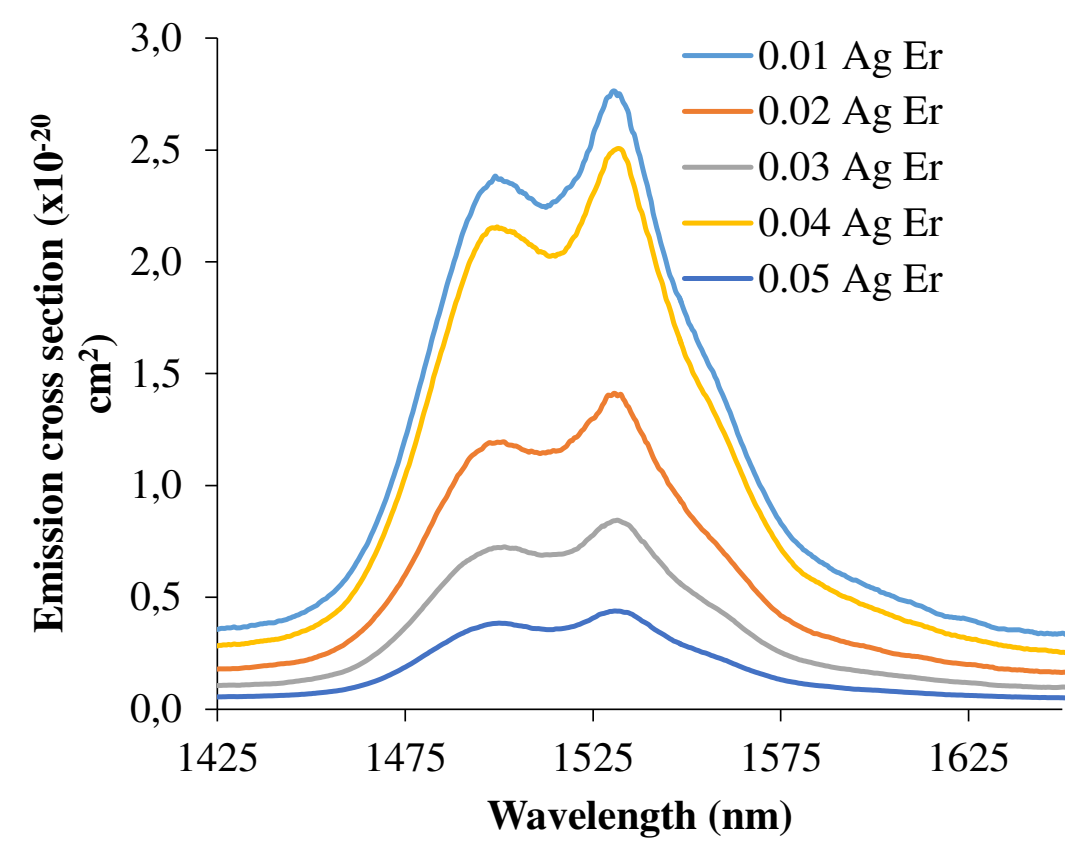

Figure 13: Emission cross section against wavelength of silver-doped erbium zinc tellurite glasses

Figure 13 presents the emission cross-section of the samples of silver-doped erbium zinc tellurite glass samples. A broad emission cross-section is one of the essential requirements for a broadband amplifier, producing a higher rate of energy extraction which is needed by the optical materials [46]. According to Hamza et al., (2019) [22], a higher value of stimulated emission cross-section promotes lower threshold and higher optical gain applications, useful for better laser performance. The threshold is the point where the first laser action occurs. Therefore, a lower threshold is good enough to initiate the first laser action. Compared to the previous literature, Choi et al., (1999), Jin et al., (2007), Rivera Lopez et al., (2012) and Zhang et al., (2012) [47-50], the current research unveils better emission cross-section which is more significant than previous works and can also be claimed as an efficient for EDFA amplification purpose [51]. Nonetheless, Ravi et al., (2015) [45] proposed that a lower value of emission crosssection is necessary for the near infrared optical amplifier at $1.53 \mu \mathrm{m}$ development. Therefore, in conclusion, the results showed that both the high and low value of emission cross-section has brought significantly different applications. 


\section{Gain coefficient analysis}

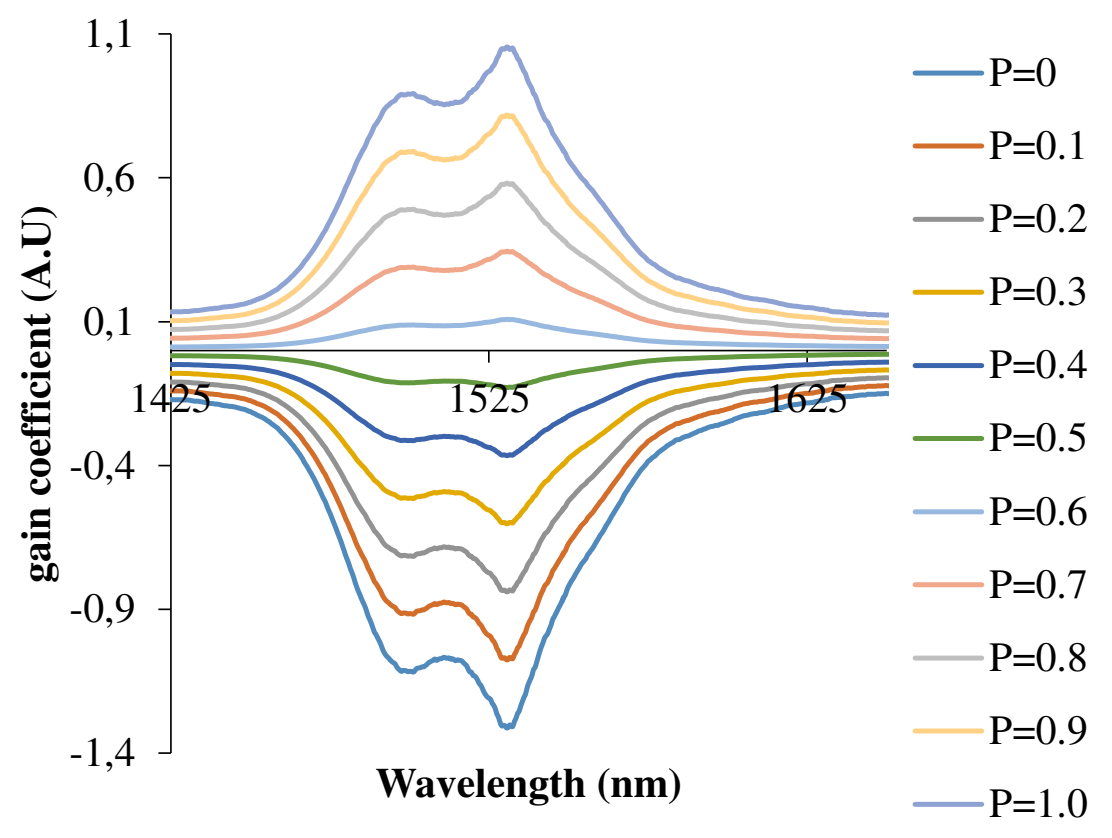

Figure 14: Optical gain against wavelength of silver-doped erbium zinc tellurite glasses

In 2019, Hamza and other co-authors had mentioned that the gain parameter is one of the crucial components to execute better laser performance. They had also mentioned that gain is utilized in order to enhance the laser media implementation and has the potential to be a broadband amplifier application. The optical gain against wavelength with the values of population inversion $(\mathrm{P})$ varying from 0 to 1.0 has been executed. The results showed that the intensity of the gain and its width increased as the value of P increased. Since the gain falls between 0.6 to 1 , the width shifted to become a shorter wavelength. The gain obtained is flat (maximum gain difference) for the population inversion of more than 0.6. The gain covers the $\mathrm{C}$ band (1530$1565 \mathrm{~nm})$ and $L$ band (1565-1625 nm) regions, which fall in the optical communication window. Furthermore, it supplies more channels in the wavelength division multiplex (WDM) networks as well [45]. WDM is a technology that multiplexes several optical carrier signals onto a signal option fibre by using laser lights with different wavelengths.

\section{Spectroscopic parameters under McCumber theory}

Table 2: Full width half maximum, gain bandwidth and figure of merit of silver-doped erbium zinc tellurite glasses

\begin{tabular}{cccc}
\hline Molar fraction, $x$ & $\begin{array}{c}\text { Full width half } \\
\text { maximum }\end{array}$ & Gain bandwidth & $\begin{array}{c}\text { A gain figure of } \\
\text { merit }\end{array}$ \\
\hline 0.01 & 67.32 & 184.45 & 3.40 \\
0.02 & 69.84 & 97.78 & 3.32 \\
0.03 & 75.14 & 624.40 & 30.41 \\
0.04 & 48.18 & 118.83 & 1.39 \\
0.05 & 90.70 & 392.71 & 10.99 \\
\hline
\end{tabular}


As tabulated in Table 1, the full width half maximum (FWHM) increases except for the 0.04 molar fraction of silver oxide. The increment of FWHM leads to a higher amount of gain bandwidth which can be inferred as an appropriate gain medium for the broadband amplifier [52, 53]. Generally, FWHM or effective band width is a measurement of the emission band which covers the S-band (1460-1530 nm), C-band (1530-1570 nm) and L-band (1570 -1630 nm). All the bands have been considered optimum for a wide range of transmission amplification purposes [54]. The two known vital criteria in gaining high performance of broadband EDFA are flat and wide gain at $1.5 \mu \mathrm{m}$ communication window. The current FWHM has successfully recorded higher values when compared to the earlier result reported by Baki et al. (2013) [21].

For an amplifier device, the gain figure-of-merit (FOM) is the product of lifetime and emission cross-section. The larger the FOM for gain, the better the competency for fibre amplifier application [55]. Gain bandwidth is another parameter to measure up the efficiency of the optical amplifier. The more significant value of GBW can infer that the complexity of the designed glass composition proposed in this work can contribute to the application of optical amplification [21].

\section{Judd-Ofelt analysis}

Table 3: Experimental $\left(\mathrm{f}_{\exp } \times 10^{-6}\right)$ and theoretical $\left(\mathrm{f}_{\text {th }} \times 10^{-6}\right)$ oscillator strength of optical transition of silver-doped erbium zinc tellurite glasses

\begin{tabular}{|c|c|c|c|c|c|c|c|c|c|c|c|}
\hline & & \multicolumn{2}{|c|}{$0.01 \mathrm{Ag}$} & \multicolumn{2}{|c|}{$0.02 \mathrm{Ag}$} & \multicolumn{2}{|c|}{$0.03 \mathrm{Ag}$} & \multicolumn{2}{|c|}{$0.04 \mathrm{Ag}$} & \multicolumn{2}{|c|}{$0.05 \mathrm{Ag}$} \\
\hline $\begin{array}{c}\text { Transition } \\
\text { (From } \\
{ }^{4} \mathrm{I}_{15 / 2} \text { ) }\end{array}$ & $\left.\begin{array}{c}\lambda\left(\mathrm{cm}^{-}\right. \\
1\end{array}\right)$ & $\mathrm{f}_{\mathrm{exp}}$ & $\mathrm{f}_{\mathrm{th}}$ & $\mathrm{f}_{\mathrm{exp}}$ & $\mathrm{f}_{\mathrm{th}}$ & $\mathrm{f}_{\mathrm{exp}}$ & $\mathrm{f}_{\mathrm{th}}$ & $\mathrm{f}_{\mathrm{exp}}$ & $\mathrm{f}_{\mathrm{th}}$ & $\mathrm{f}_{\text {exp }}$ & $\mathrm{f}_{\mathrm{th}}$ \\
\hline${ }^{4} \mathrm{I}_{13 / 2}$ & 6604 & 3.799 & 5.208 & 2.170 & 2.652 & 1.409 & 1.703 & 4.206 & 10.99 & 1.069 & 2.369 \\
\hline${ }^{4} \mathrm{I}_{11 / 2}$ & 10234 & 2.762 & 1.955 & 1.841 & 1.325 & 1.196 & 0.882 & 3.432 & 4.665 & 0.820 & 1.015 \\
\hline${ }^{4} \mathrm{I}_{9 / 2}$ & 12484 & 4.733 & 1.861 & 2.127 & 0.991 & 1.382 & 0.653 & 3.957 & 0.684 & 0.889 & 0.096 \\
\hline${ }^{4} \mathrm{~F}_{9 / 2}$ & 15274 & 9.915 & 10.21 & 5.017 & 5.223 & 3.259 & 3.399 & 8.732 & 10.08 & 1.671 & 1.994 \\
\hline${ }^{4} \mathrm{~S}_{3 / 2}$ & 18290 & 30.64 & 1.952 & 15.42 & 0.910 & 10.01 & 0.574 & 28.01 & 4.617 & 5.213 & 1.004 \\
\hline${ }^{2} \mathrm{H}_{11 / 2}$ & 19135 & 8.305 & 7.452 & 4.029 & 23.49 & 2.617 & 17.11 & 6.866 & 6.774 & 1.330 & 1.315 \\
\hline${ }^{4} \mathrm{~F}_{7 / 2}$ & 20412 & 32.05 & 8.667 & 16.54 & 4.204 & 10.74 & 2.689 & 29.19 & 15.31 & 5.516 & 3.256 \\
\hline${ }^{4} \mathrm{~F}_{5 / 2}$ & 22145 & 19.49 & 2.385 & 9.492 & 1.109 & 6.166 & 0.699 & 16.00 & 5.628 & 2.869 & 1.223 \\
\hline${ }^{4} \mathrm{~F}_{3 / 2}$ & 24624 & 34.86 & 1.511 & 18.10 & 0.703 & 11.76 & 0.443 & 32.15 & 3.566 & 6.063 & 0.775 \\
\hline${ }^{2} \mathrm{G}_{9 / 2}$ & 26279 & 223.5 & 3.275 & 107.5 & 1.552 & 69.84 & 0.985 & 196.8 & 6.874 & 35.21 & 1.488 \\
\hline
\end{tabular}

Table 4: Judd-Ofelt parameters $\left(\Omega_{2}, \Omega_{4}\right.$ and $\left.\Omega_{6}\right)$ and spectroscopic quality factor $\left(\Omega_{4} / \Omega_{6}\right)$ of silver-doped erbium zinc tellurite glasses

\begin{tabular}{ccccc}
\hline $\begin{array}{c}\text { Molar fraction, } \\
\mathrm{y}\end{array}$ & $\Omega_{2}\left(\mathrm{x} 10^{-20}\right)$ & $\Omega_{4}\left(\mathrm{x} 10^{-20}\right)$ & $\Omega_{6}\left(\mathrm{x} 10^{-20}\right)$ & $\Omega_{4} / \Omega_{6}$ \\
\hline 0.01 & 0.0204 & 4.7575 & 2.7572 & 1.7255 \\
0.02 & 8.0127 & 2.4753 & 1.2476 & 1.9840 \\
0.03 & 5.8994 & 1.6194 & 0.7801 & 2.0759 \\
0.04 & 1.1204 & 1.3703 & 6.2169 & 0.2204 \\
0.05 & 0.2506 & 0.1616 & 1.3184 & 0.1226 \\
\hline
\end{tabular}


Table 5: Evaluated values of transition probabilities, $\mathrm{A}\left(\mathrm{s}^{-1}\right)$, branching ratio, $\beta(\%)$ and radiative lifetime, $\tau_{\mathrm{r}}(\mathrm{ms})$ of silver-doped erbium zinc tellurite glasses

\begin{tabular}{ccccccccc}
\hline \multicolumn{2}{c}{ Transitions } & $\begin{array}{c}\lambda \\
\left(\mathrm{cm}^{-1}\right)\end{array}$ & $\begin{array}{c}\text { Parameter } \\
\mathrm{s}\end{array}$ & $0.01 \mathrm{Ag}$ & $0.02 \mathrm{Ag}$ & $0.03 \mathrm{Ag}$ & $0.04 \mathrm{Ag}$ & 0.05 \\
$\mathrm{Ag}$
\end{tabular}

Table 6: Evaluated values of Racah parameters (R and C), crystal field parameters $\left(D_{q}\right.$ and $\left.D_{q} / R\right)$ and nephelauxetic ratio, B' and bonding parameters $\left(\boldsymbol{\delta}\right.$ and $\left.\mathrm{b}^{1 / 2}\right)$

\begin{tabular}{cccccccc}
\hline $\begin{array}{c}\text { Molar } \\
\text { fraction, } \\
\mathrm{X}\end{array}$ & $\mathrm{B}^{\prime}$ & $\boldsymbol{\delta}$ & $\mathrm{b}^{1 / 2}$ & $\mathrm{D}_{\mathrm{q}}$ & $\mathrm{R}$ & $\mathrm{C}$ & $\mathrm{D}_{\mathrm{q}} / \mathrm{R}$ \\
\hline 0.01 & 1.00041 & -0.04100 & -0.02050 & 1829.0 & 71.29 & 612.29 & 25.66 \\
0.02 & 1.00031 & -0.03100 & -0.01559 & 1828.0 & 71.28 & 582.29 & 25.65 \\
0.03 & 1.00021 & -0.02100 & -0.01050 & 1827.0 & 71.27 & 552.29 & 25.63 \\
0.04 & 1.00011 & -0.01100 & -0.00550 & 1829.0 & 71.29 & 612.29 & 25.66 \\
0.05 & 1.00001 & -0.00010 & -0.00500 & 1828.0 & 71.28 & 582.29 & 25.65 \\
\hline
\end{tabular}


Mahraz et al., (2015) [39] had reported that Judd-Ofelt theory is used to identify the spectroscopic parameters from absorption spectra. Soltani et al., (2015) [46] had mentioned that the absorption spectra could be utilized to determine the radiative transition probabilities, branching ratio and a radiative lifetime of different transitions particularly by using Judd-Ofelt theory. The comparison between the experimental and theoretical line strength listed in Table 2 can verify the fitting. By employing the least-square fitting technique, the Judd-Ofelt parameters $\Omega_{\lambda}(\lambda=2,4,6)$ of erbium oxide co-doped with silver oxide on zinc tellurite glasses are shown in Table 3. Judd Ofelt parameters on the glass materials of the transition probabilities can be further discussed in crystal field parameters, interconfigurational radials integral and the interaction between the central ion and the intermediate environment.

The oscillator strength gives indirect information within the glass matrixon the symmetry and the bonding of the rare-earth ions. In other words, oscillator strength can be identified as the probability of absorption or emission of electromagnetic radiation transition within the glass matrix. Small values of oscillator strength indicate high symmetry around the rare-earth ions. Some transitions are very sensitive to small changes in the environment around erbium ions and are called hypersensitive transition (HSTs). The most intense absorption bands of the glass series transition are ${ }^{4} \mathrm{I}_{15 / 2}$ to ${ }^{2} \mathrm{G}_{9 / 2}$ due to HSTs. The outcome will lead to the generation of a high number of non-bridging oxygen and, then, the asymmetry of the bond will increase and spread to the neighbouring network cations.

The change that is taking place in the erbium ions site symmetry is due to the accretion of silver oxide into a glass matrix. This will result in the reduction in site symmetry of the bond between ligand network cations (glass host) and the active ions (lanthanide ions). The phenomenon leads to higher asymmetry within the rare-earth ion and glass matrix by forming numbers of nonbridging oxygen from bridging oxygen. Besides that, adding silver oxide in the glass matrix will increase in the site asymmetry of erbium ions (lower symmetry). The improved intensity and oscillator strength in the (HSTs) transition reveal more created covalent bonds [56].

The $\Omega_{2}$ parameters values indicate the asymmetry of the erbium ions in the local environment, which affects by the covalence between erbium ions and ligand anions. In the meantime, the value of the $\Omega_{6}$ parameter is related to the local basicity of erbium ions. It is reversible to the covalence of the erbium oxide bond. Fares et al., (2014) and Mahraz et al., (2015) [39,57] had reported that $\Omega_{2}$ is sensitive to the asymmetry in the region of the rare-earth ions (short-range effect). On the other hand, the differences in $\Omega_{4}$ and $\Omega_{6}$ are interrelated to the long-range effect of the glass host. In 2017, Mawlud and other co-authors [58] reported that $\Omega_{2}$ is affected by the strength of the bond between the rare-earth ions and the ligand ions. There is a high possibility of the asymmetry and polarization of the local structure surrounding the rare earth ion causing this phenomenon. However, $\Omega_{4}$ and $\Omega_{6}$ reflects the bulk properties of host glass, for instance, density and rigidity.

As tabulated in Table 3, the trend of $\Omega_{2}$ for the glass series is predicted to be non-linear. The highest $\Omega_{2}$ values for erbium-co-doped silver of zinc tellurite glass system are obtained at 0.02 molar fraction. The phenomenon indicates strong covalence of ions-ligand and high asymmetry of the local surrounding of erbium ions. And thus, this phenomenon creates a higher degree of covalence in the glass network. This can be associated with the weak interaction between erbium 
ions and silver ions that affect the crystal field environment of erbium ions. The increment of $\Omega_{2}$ can be related to the increase in polarization and asymmetry of the rare earth ions site [55]. In addition, a stronger value of $\Omega_{2}$ indicates less centro-symmetrical ions site and a less ionic bond between rare-earth ions and the ligands. A higher value of $\Omega_{2}$ is caused the partially broken or forbidden transition for lower symmetry in the crystal field.

The increment in values of silver oxide concentration indicates lower symmetry in the structural coordination surrounding the erbium ions. The symmetry of rare-earth ion sites decreased because the enhancement of non-bridging oxygen ions in the glass system increased the $\Omega_{2}$. The increase of this parameter will cause the lower symmetry in the structural coordination surrounding the erbium ions. The increment of this parameter can increase in covalence, socalled a nephelauxetic shift at the rare-earth sites [37,39].

Nevertheless, the decreasing values of $\Omega_{2}$ with the addition of dopants concentration indicates a long-range structural disorder effect and decrease in asymmetric behaviour of the crystal field [46]. In 2017, Mahraz and other co-workers reported that the changes in Judd-Ofelt parameters are related to the incorporation of the silver ion. The outcome of these changes can change the ligand field of erbium ions [59].

In contrast to $\Omega_{2}$ and $\Omega_{4}$ proposed by Fares et al., (2014) [57], the $\Omega_{6}$ parameter is independent of the local structure, yet it is reliable to the rigidity and density of the prepared glasses. The concentration of 0.03 molar fractions of erbium possesses the lowest value of $\Omega_{6}$. The phenomenon is the cause of the decrement in the rigidity between the erbium ion and ligand bonds. The decreasing trend of $\Omega_{6}$ can be associated with the changes of the structural units that depend on the composition and structure of the glass host itself. In 2017, Moustafa et al. [56] had mentioned that the inclusion of silver oxide signifies the improvement of the covalence nature of the Er-O bond, which will affect the structural units of the glasses (environment of the glasses).

$\Omega_{6}$ reaches its highest value at 0.04 molar fraction of silver oxide. The increasing values of $\Omega_{6}$ indicate more covalence between erbium ions and ligand atoms. The vibrational amplitude of the erbium oxide bond increases with $\Omega_{6}$. According to Faris et al., (2014) [57], the increment of $\Omega_{6}$ can be associated with more presence of Er cations that dissolve in the glass matrix. Eventually, it leads to the adjacent between Er cations diminishing. This explanation can be further supported by the increment of the repulsive force at the surrounding of Er cations. Besides that, the nonlinear variation trend of $\Omega_{6}$ is because the composition of the glass system is controlling the structural change. The increasing value of $\Omega_{6}$ between 0.03 and 0.04 molar fraction of silver oxide co-doped with erbium oxide enhances the large stark splitting energy level of erbium ions. This will enhance the broadening of the emission band. The rigidity of the host glass indicated by the $\Omega_{6}$ will be higher as a result of the presence of silver oxide within the glass network [39].

$\Omega_{4}$ is influenced by the factors of the difference in both $\Omega_{2}$ and $\Omega_{6}$, especially, if the changes of $\Omega_{2}$ and $\Omega_{6}$ are opposite. In this case, the $\Omega_{4}$ will affect some transition of erbium ions along with $\Omega_{6}$, such as from ${ }^{2} \mathrm{H}_{11 / 2}$ to ${ }^{4} \mathrm{I}_{15 / 2}$ transition. Based on Jacob and Weber theory, the $\Omega_{4}$ and $\Omega_{6}$ parameters can uniquely characterize the erbium emission intensity. This situation can be called as spectroscopic quality factor $\left(\Omega_{4} / \Omega_{6}\right)$. The small amount of this parameter leads to a more intense laser transition. The spectroscopic quality factor $(\mathrm{X})$ is an essential measure in laser- 
active medium to illustrate the stimulated emission as the behaviour of discrete lasing transition in laser optical material. In research work reported by Fares et al., (2014), Soltani et al., (2015) and Mahraz et al., (2015) [39,46,57], they had proposed that a small amount of this ratio lead to more intense laser transition of ${ }^{2} \mathrm{I}_{13 / 2}$ to ${ }^{4} \mathrm{I}_{15 / 2}$. The essential role of silver oxide is exhibited when its presence reduces the quality factor in the fluorescence dynamics of the erbium ions doped glass system.

Faris et al., (2014) [57] had mentioned that the radiative transition probability is the transition from the upper manifold states to their corresponding lower-lying manifold states. The evaluated probabilities of radiative transition of silver-co-doped erbium zinc tellurite glasses are tabulated in Table 4. It can be noticed that the radiative probability, $\mathrm{A}_{\mathrm{rad}}$ of erbium is advantageous to the blue, green and red emission for the glass series. The attained value of $\delta_{\text {rms }}$ deviation is $0.3833430 \times 10^{-20} \mathrm{~cm}^{2}$ for the glass series. The experimental value displays a good accord with calculated value data and consequently promotes a high precision to determine the intensity parameters.

The luminescence branching ratio can attain stimulated emission from any specific transition showed how it is a crucial parameter for the laser design. The branching ratio parameter also represents the decay or depopulation of particular atoms. The attained data for fluorescence branching ratio and a radiative lifetime of the glass series are tabulated in Table 4 . The intensity of an emission line is determined by using the fluorescence branching ratio at a given excited state. The area of emission peaks can determine the experimental branching ratio. The branching ratio for silver-co-doped erbium zinc tellurite glasses is what can be observed in this study at most transition. The attained result explains that the present glasses correspond to blue, green and red emission with the respective glass series that depopulates from that level. This is also reported by Mahraz et al., (2015) [39] that the values of the branching ratio that lies in the particular transition can achieve efficient blue, green and red emission under suitable excitation condition in the glasses.

Other than that, the lifetime is crucial for optical amplifier and laser application, especially at the $1.53 \mu \mathrm{m}$ band. Mahraz et al., (2015) [39] had reported that a radiative lifetime is a parameter on how rapid a particular level gets depopulated. The transition of ${ }^{4} \mathrm{I}_{13 / 2}$ level has a longer lifetime benefits the population inversion between the ${ }^{4} \mathrm{I}_{13 / 2}$ and ${ }^{4} \mathrm{I}_{15 / 2}$ levels [60]. It is noticed that the lifetime of silver-co-doped erbium zinc tellurite glasses is higher at ${ }^{4} \mathrm{I}_{13 / 2} \rightarrow{ }^{4} \mathrm{I}_{15 / 2}$ transition level. The unique properties of silver oxide in the erbium zinc tellurite glasses have brought to the decrement in a radiative lifetime for faster decay. The properties mentioned cause the substantial emission probabilities enhance optical transition.

As tabulated in Table 5, both bonds parameters are negative, showing an erbium ion ligand possess an ionic bonding [22-23]. However, the bonds decrease with the increasing of silver oxide concentration. This is correlated to the weaker ionic bond between the host glass and the erbium ions ligand as it shifts towards higher values $[23,61]$. The decrement also rectifies the ionic bonds turn to the character of covalence bonding. Kothari in 2014 [61] had also reported that by using Slater-Condon parameters, the trend of the bonding parameter of $b^{1 / 2}$ is slightly similar to $\boldsymbol{\delta}$, which indicates the changes bond from ionic weaker to become covalence bond. 
Racah parameters ( $\mathrm{R}$ and $\mathrm{C}$ ) are very convenient in calculating the covalence of the liganddopant bond. It is also used to measure the inter-electronic repulsion in the d-shell. Larger R and $\mathrm{C}$ values will localize more electrons on the transition metal ions [23]. The decrement of racah parameters provide stronger covalence bonds characteristics. In 2019, Hamza and other coauthors [22] had mentioned that the decrement of these parameters could be attributed to the larger orbital size.

The strength of the crystal site is given by the $\mathrm{D}_{\mathrm{q}} / \mathrm{R}$ as shown in Table 6 [23]. The results showed that the increment of silver oxide concentration leads the crystal field strength to improve. The possible explanation is that the existence of silver oxide in the interstitial sites is causing the contraction of erbium ions. Besides that, the value of $D_{q} / R$ is more than 2.3 , which exhibits the crystal structure has strong sites [22,25]. Moreover, the crystal field sites increased by increasing the electronegativity. This phenomenon is because of electronegativity that played the role to deform the crystal ions around the transition metal ions.

\section{CIE Analysis}

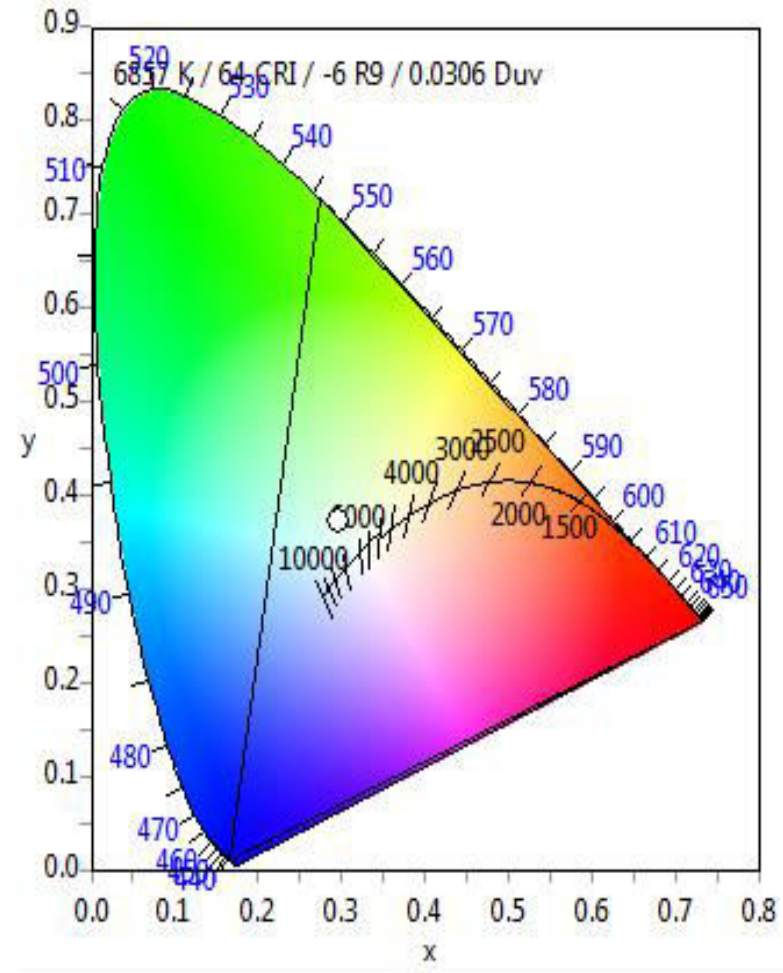

Figure 15: CIE 1931 chromaticity diagram of 0.01 molar fraction of silver oxide

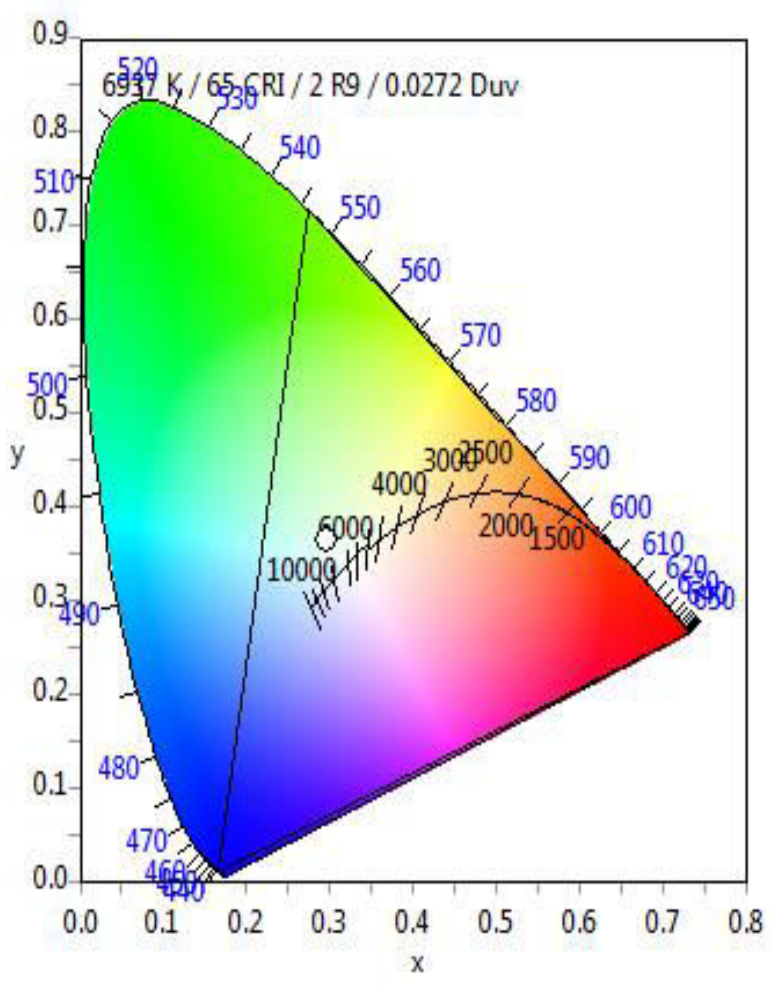

Figure 16: CIE 1931 chromaticity diagram of 0.02 molar fraction of silver oxide 


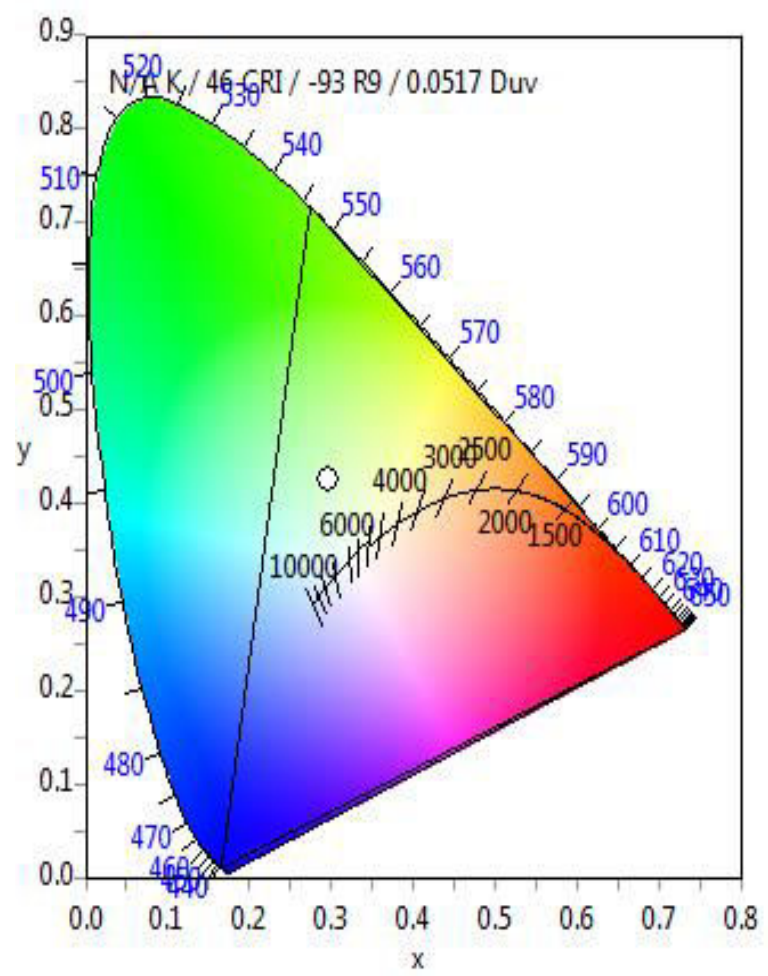

Figure 17: CIE 1931 chromaticity diagram of 0.03 molar fraction of silver oxide

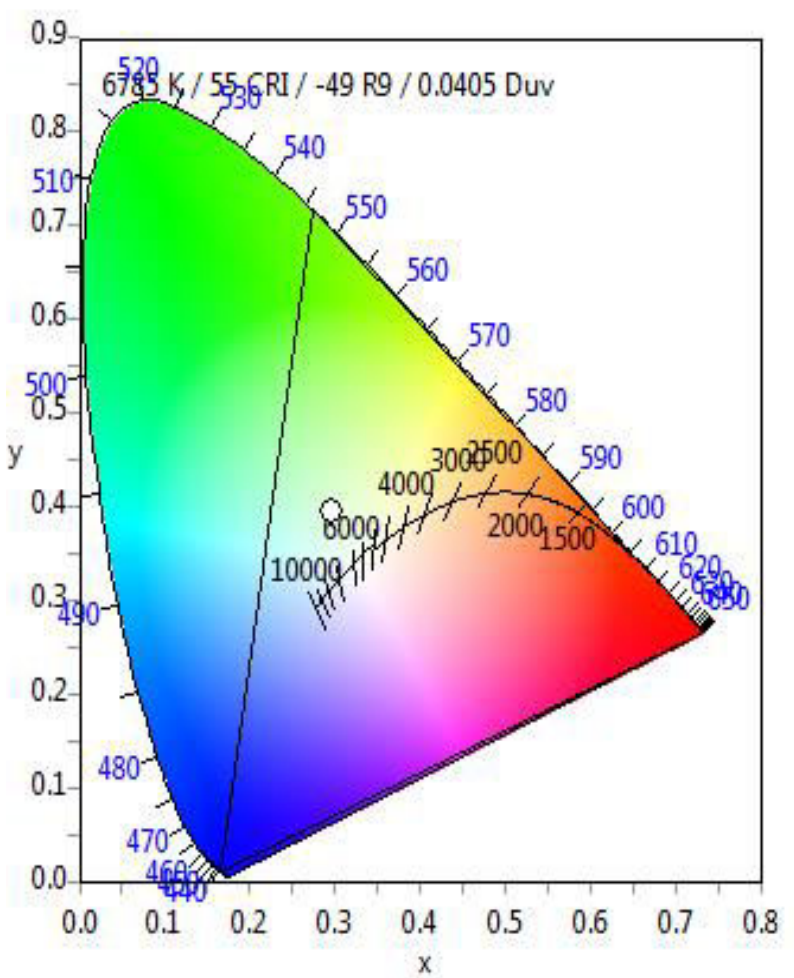

Figure 18: CIE 1931 chromaticity diagram of 0.04 molar fraction of silver oxide 


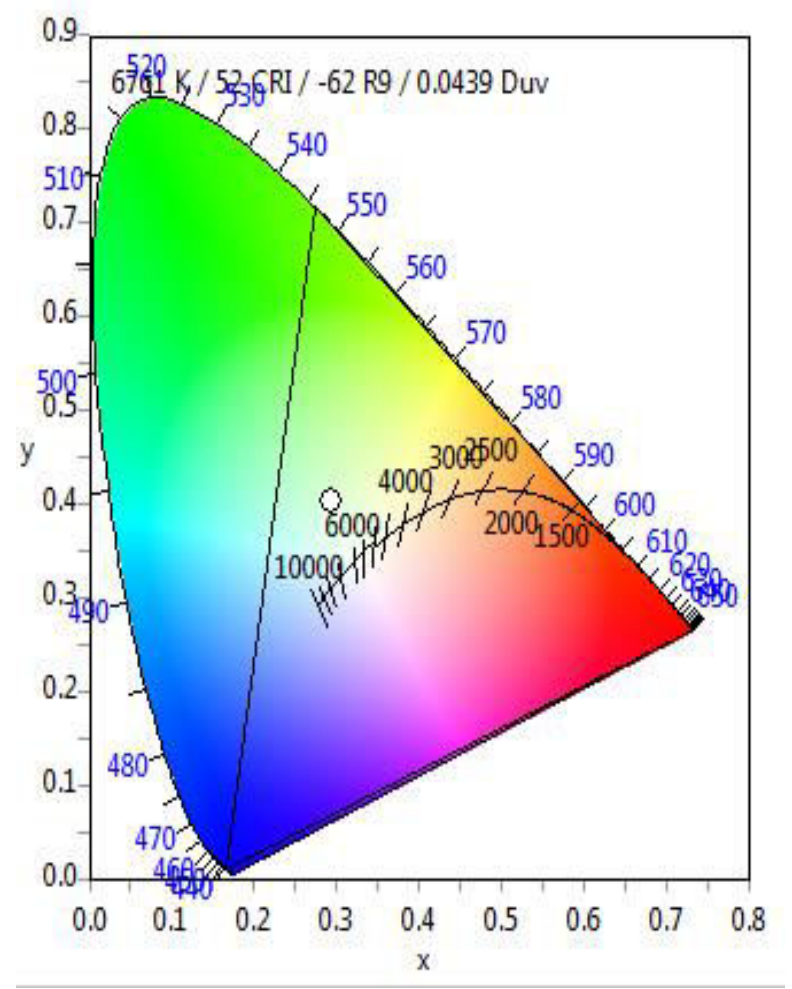

Figure 19: CIE 1931 chromaticity diagram of 0.05 molar fraction of silver oxide

The emission spectra were characterized by the CIE 1931 chromaticity diagram to charaterize the dominant emission colour of the prepared glasses. The $(\mathrm{x}, \mathrm{y})$ coordinates of the present $\mathrm{Er}^{3+} / \mathrm{Ag}$ doped zinc tellurite glasses were reported in Table 7. Figures 15 to 19 showed the CIE 1931 chromaticity diagram of the studied glasses CIE, and what can be observed is that the (x,y) coordinates pass through the white light region of the CIE 1931 chromaticity diagram [62-64]. [62-64]. Commonly, the standard equal energy point $(0.33,0.33)$ of the white light emission always located at the centre of the CIE diagram. The stability of the present glasses for white light applications is an indication of the colour coordinates located nearer to the standard equal energy points. The quality of any light source shows the temperature of the nearest black body radiation to the operating point in the CIE diagram. The quality mentioned can be examined in terms of correlated colour temperature (CCT). Higher values of CCT will produce light with more excellent visual acuity and higher brightness perception than lower CCT values [65].

The calculated CCT values of the present glasses were shown in Table 7 and found to vary from 6761 to $6937 \mathrm{~K}$. The values are comparative to the commercial LCD (liquid crystal display) and CRT (cathode ray tube) screens. This phenomenon indicates that current glasses can give cool white light emission under UV excitation, which is related to the statement made by Soares et al. in 2011 [65]. For white LED applications, the discovery of colour purity of the dominant emission colour is crucial and, it should be as low as possible to achieve pure white light emission. The colour purity of the title glasses was obtained using colour calculator v.7 77 software and, the colour purity values were $10.7 \%, 10.7 \%, 18.8 \%, 12.8 \%$, and $14.0 \%$ for the respective glass samples [66]. 
To correlate with the photoluminescence spectra, it confirms that $375 \mathrm{~nm}$ excitation wavelength emits in the blue, green and red regions, as shown in Figure 8. Therefore, these materials can be used as luminescent material within these three colour regions [67].

Table 7: CIE chromaticity coordinates, CCT and purity values of silver-doped erbium zinc tellurite glass system

\begin{tabular}{|c|c|c|c|c|}
\hline \multirow[t]{2}{*}{ Molar fraction, $\mathrm{x}$} & \multicolumn{2}{|c|}{ CIE Chromaticity coordinates } & \multirow[t]{2}{*}{$\mathrm{CCT}(\mathrm{K})$} & \multirow[t]{2}{*}{ Purity (\%) } \\
\hline & $\mathrm{x}$ & $\mathrm{y}$ & & \\
\hline 0.01 & 0.2982 & 0.3726 & 6857 & 10.7 \\
\hline 0.02 & 0.2979 & 0.3645 & 6937 & 10.7 \\
\hline 0.03 & 0.2956 & 0.4244 & 6743 & 18.8 \\
\hline 0.04 & 0.2960 & 0.3946 & 6785 & 12.8 \\
\hline 0.05 & 0.2952 & 0.4026 & 6761 & 14.0 \\
\hline
\end{tabular}

\section{Structural properties}

\section{X-ray diffraction (XRD) analysis}

The verification of all the applications made by the glass can be done by using X-ray diffraction (XRD), which is one of the characterizations methods used to determine the structure of the materials. Therefore, XRD was utilized to determine whether the synthesized glass sample is amorphous or crystalline. Glass is usually amorphous when it shows a non-crystalline state. The phenomenon is proved by using the XRD spectra of the glass series are illustrated in Figure 20. The spectra were recorded under room condition with a temperature in the range of $20^{\circ} \leq \Theta \leq$ $80^{\circ}$.

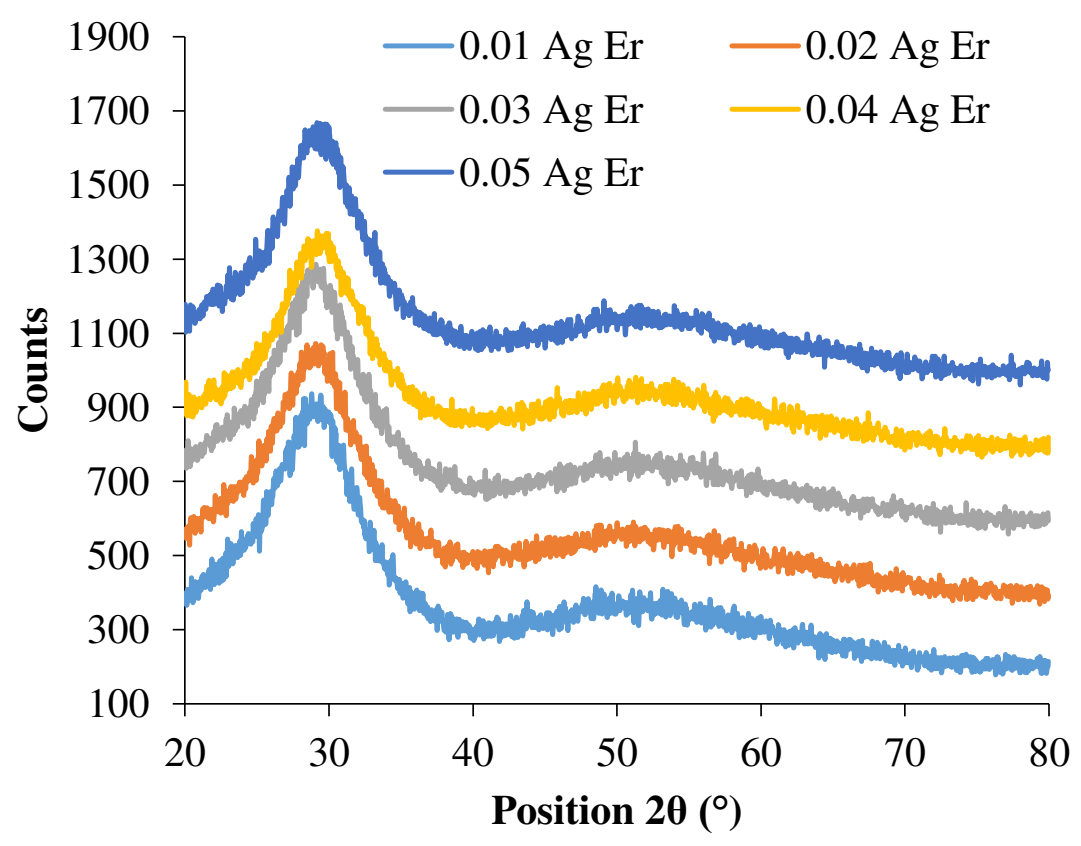

Figure 20: XRD patterns of silver-doped erbium zinc tellurite glasses

As portrayed in Figure 20, the XRD spectra for the present glass series successfully shows a wide diffusion hump at lower scattering angles. The results indicate the lack of long-range 
structural order in the glass samples. The absence of sharp peak or the existence of broad hump around $2 \theta=30^{\circ}$ or in other words confirms the non-existence of the crystalline phases in the material. Furthermore, the phenomenon proves that the glass series is entirely amorphous [38]. Cai et al. (2016) [68] supports the argument that the absence of long-range atomic arrangement in the glass system confirms the amorphous nature of the glass samples.

\section{Physical properties}

\section{Density and molar volume analysis}

The density parameter has been an indicator in this subtopic to identify the strength of the glasses. Density can be defined as a degree of compactness of the substance as well as the strength of the amorphous materials [69-71]. Kumar et al., (2011) [70] had mentioned that the density would affect the transformation in geometrical configuration, coordination number, cross-link density, interstices spaces and the compactness of the materials. The density of the prepared glass samples is evaluated by using distilled water as an immersion liquid. The evaluation is done by using Archimedes' principle at room temperature. On the other hand, the molar volume can be defined by identifying the changes in the structure of the glass sample. Wang et al., (1994) [72] had reported that the changes in molar volume rely on the behaviour of the density and molecular weight of the elements in the glass system.

Table 8: Density and molar volume of silver-doped erbium zinc tellurite glasses

\begin{tabular}{ccc}
\hline Molar fraction, $\mathrm{x}$ & Density $\left(\mathrm{g} / \mathrm{cm}^{3}\right)$ & Molar volume $\left(\mathrm{cm}^{3} / \mathrm{mol}\right)$ \\
\hline 0.01 & 4.4673 & 32.8713 \\
0.02 & 4.5775 & 32.2672 \\
0.03 & 4.7138 & 31.5161 \\
0.04 & 4.8219 & 30.9874 \\
0.05 & 4.9705 & 30.2335 \\
\hline
\end{tabular}

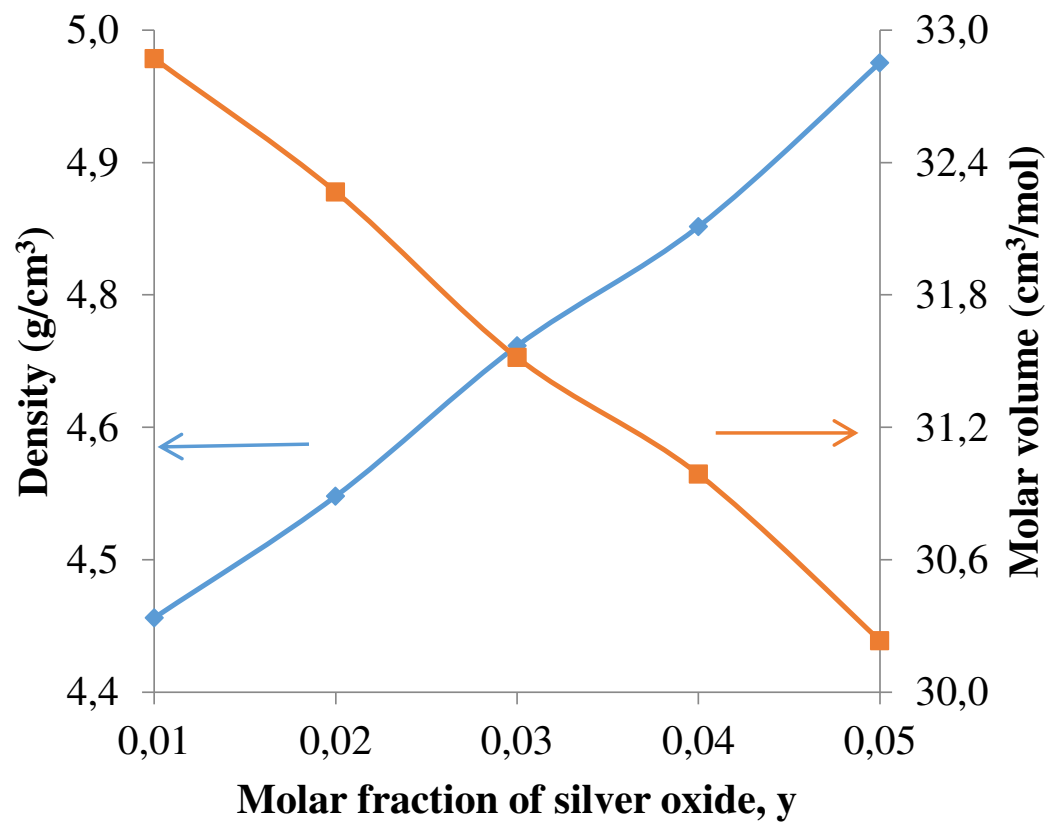

Figure 21: Graph of density and molar volume of silver-doped erbium zinc tellurite glasses 
Figure 21 shows the relationship between density and molar volume concerning the molar fraction of silver oxide. Based on the result acquired, the density of the glass samples increases as the concentration of silver oxide increases, which can be related to the addition of dopants in the glass system. In silver-doped glasses, the increment in the density of the glass samples is caused by the substitution of a lighter atom with the heavier atom [38,73]. When lower atomic mass of Te $(127.6 \mathrm{~g} / \mathrm{mol})$ and $\mathrm{Zn}(65.38 \mathrm{~g} / \mathrm{mol})$ is replaced by the combination of $\operatorname{Er}(167.3$ $\mathrm{g} / \mathrm{mol})$ and $\mathrm{Ag}(107.87 \mathrm{~g} / \mathrm{mol})$, the overall atomic mass of the glass sample increases. In other words, the addition of elements with greater atomic mass makes the glass sample to become denser. Therefore, the elevation of the density of the glass sample enhances the compactness of the glass sample. Other than that, the addition of the combination of erbium oxide and silver oxide will also lead to an increment in the average molecular weight [38]. The incorporation of a huge molecular weight of erbium oxide (382.52 and silver oxide $(231.74 \mathrm{~g})$ will enhance the density of the glass system as compared to tellurium oxide $(159.60 \mathrm{~g})$ and zinc oxide $(81.38 \mathrm{~g})$ [74]. Besides that, the increased density is due to more oxygen, which diverts the trigonal pyramid into the trigonal bipyramid [75]. The presence of the trigonal pyramid and trigonal bipyramid is proven through FTIR and deconvolution result that can be strongly related to the formation of NBO and BO in the glass system. Hence, the density that increased with dopants' content in the glass system will produce more rigid and quality glass [76].

The graph of molar volume concerning the molar fraction of silver oxide is depicted in Figure 21. The molecular weight of the overall glass system has a crucial role in increasing density and decreasing the molar volume. When the concentration of silver oxide increases, the sample becomes more compact since there is no expansion of free volume in the glass system. The decrement in molar volume can be proven by the theoretical relationship between density and molar volume where the decrement of the molar volume is affected by the increment in density [57]. Saddeek et al., (2015) [78] reported the trend of molar volume for this quaternary glass system follows its theoretical relationship with density. The results showed that the density and molar volume displays the constrating behavior between each other.

\section{Conclusion}

A series of zinc tellurite glasses doped with erbium oxide and silver oxide was fabricated by using the melt-quenching technique. Since there is no sharp peak observed from the XRD analysis, all glass samples are amorphous. Density analysis displays the increment in density from 4.4673 to $4.9705 \mathrm{~g} / \mathrm{cm}^{3}$ and decrement from 32.87 to $30.23 \mathrm{~cm}^{3} / \mathrm{mol}$ of molar volume, which improves the rigidity of the glass system. From the results of the UV-Vis analysis, the absorption bands were observed using silver oxide as the dominant dopant and erbium oxide as the co-dopant in the glass series. The displayed bands are attributed to the role of erbium oxide as the $4 \mathrm{f}-4 \mathrm{f}$ transition elements, which promotes the transition of the electron in different energy levels. Three possible emissions which consist of blue, green and red were detected in the photoluminescence spectra under $375 \mathrm{~nm}$ excitation wavelength. For McCumber theory, having a higher emission cross-section and higher FWHM is efficient for both the broadband amplifier and laser application. Wider and flatter gain with a maximum gain difference which has covered both $\mathrm{C}$ and $\mathrm{L}$ bands are beneficial for optical communication. Besides that, it can supply more channels in the wavelength division multiplex network (WDM). A higher gain figure of merit and larger gain bandwidth are used to justify the efficiency of optical amplification. Under 
investigation of McCumber theory, 0.03 molar fraction is the most significant glass sample for all application, as mentioned earlier. The Judd-Ofelt analysis was focused on the spectroscopic quality factor and lifetime parameter. A small amount of spectroscopic quality factor is believed to produce a more intense laser transition which is crucial in the laser-active medium for laser optical material. Whilst, lifetime is beneficial for optical amplifier and laser application at 1.53 $\mu \mathrm{m}$ band. Shorter lifetime is responsible for a quicker decay for better and strong emission's probabilities as well as encouraging the optical transition. The present glass series also had proven the ability to be a white light application as it passes through the white light region. The present glass has the standard equal energy point of the white light emission situated near the centre of the CIE diagram $(0.33,0.33)$. On top of that, the quality of light was also observed through the correlated colour temperature (CCT). Higher values CCT of the current glass ranging from 6761 to $6937 \mathrm{~K}$ form light with better visual acuity and brighter brightness than lower CCT. Colour purity is vital for the white LED applications and, lower purity is convenient for pure white light emission. Lower colour purity was found around 10.7 to $18.8 \%$ for all the present glass series.

Although all the glass samples are suitable for the selected application, at 0.05 molar fraction of silver oxide, it has been the most convenient and significant to be used for all desired applications since it obeys all the conditions for every parameter.

\section{Acknowledgement}

We would like to expand the gratefulness to the authors of the Deanship of Scientific Research at King Khalid University, Saudi Arabia for funding this work through the General Research Program under grant number G.R.P/78/42.

\section{References}

1) McLaughlin, J. C., Tagg, S. L., Zwanziger, J. W., Haeffner, D. R., \& Shastri, S. D. (2000). The structure of tellurite glass: a combined NMR, neutron diffraction, and X-ray diffraction study. Journal of non-crystalline solids, 274(1-3), 1-8.

2) Blanchandin, S., Champarnaud-Mesjard, J. C., Thomas, P., \& Frit, B. (2000). Crystal structure of $\mathrm{BiNbTe}_{2} \mathrm{O}_{8}$. Solid State Sciences, 2(2), 223-228.

3) Salim, M. A., Khattak, G. D., Fodor, P. S., \& Wenger, L. E. (2001). X-ray photoelectron spectroscopy (XPS) and magnetization studies of iron-vanadium phosphate glasses. Journal of non-crystalline solids, 289(1-3), 185-195.

4) Halimah, M. K., Daud, W. M., Sidek, H. A. A., Zaidan, A. W., \& Zainal, A. S. (2010). Optical properties of ternary tellurite glasses. Materials Science-Poland, 28(1), 173-180.

5) Lasbrugnas, C., Thomas, P., Champarnaud-Mesjard, J. C., Merle-Méjean, T., \& Mirgorodsky, A. (2002). Glass formation study within the $\mathrm{TeO}_{2}-\mathrm{TlF}$ and $\mathrm{Tl}_{2} \mathrm{Te}_{3} \mathrm{O}_{7}-\mathrm{TlF}$ systems. Comptes Rendus Chimie, 5(8-9), 607-610.

6) Hajer, S. S., Halimah, M. K., Azmi, Z., \& Azlan, M. N. (2014). OPTICAL PROPERTIES OF ZINC-BOROTELLURITE DOPED SAMARIUM. Chalcogenide Letters, 11(11).

7) Sabadel, J. C., Armand, P., Cachau-Herreillat, D., Baldeck, P., Doclot, O., Ibanez, A., \& Philippot, E. (1997). Structural and nonlinear optical characterizations of tellurium oxidebased glasses: $\mathrm{TeO}_{2}-\mathrm{BaO}-\mathrm{TiO}_{2}$. Journal of Solid State Chemistry, 132(2), 411-419. 
8) Mohd Zaid, M. H., Matori, K. A., Abdul Aziz, S. H., Zakaria, A., \& Mohd Ghazali, M. S. (2012). Effect of $\mathrm{ZnO}$ on the physical properties and optical band gap of soda lime silicate glass. International journal of molecular sciences, 13(6), 7550-7558.

9) Rowell, N. L., Lockwood, D. J., Karmous, A., Szkutnik, P. D., Berbezier, I., \& Ronda, A. (2008). Photoluminescence of Ge nanocrystals self-assembled on $\mathrm{SiO}_{2}$. Superlattices and Microstructures, 44(4-5), 305-314.

10) Miniscalco, W. J., \& Quimby, R. S. (1991). General procedure for the analysis of Er ${ }^{3+}$ cross sections. Optics letters, 16(4), 258-260.

11) Tian, Y., Li, B., Chen, R., Xia, J., Jing, X., Zhang, J., \& Xu, S. (2016). Thermal stability and $2.7 \mu \mathrm{m}$ spectroscopic properties in Er3+ doped tellurite glasses. Solid State Sciences, 60, 17-22.

12) Rasool, S. N., Jamalaiah, B. C., Suresh, K., Moorthy, L. R., \& Jayasankar, C. K. (2017). Spectroscopic properties of $\mathrm{Er}^{3+}$-doped phosphate based glasses for broadband $1.54 \mu \mathrm{m}$ emission. Journal of Molecular Structure, 1130, 837-843.

13) Agazzi, L., Wörhoff, K., Kahn, A., Fechner, M., Huber, G., \& Pollnau, M. (2013). Spectroscopy of upper energy levels in an $\mathrm{Er}^{3+}$-doped amorphous oxide. JOSA B, 30(3), 663-677.

14) Ter-Mikirtychev, V., \& Ter-Mikirtychev, V. (2014). Optical properties and optical spectroscopy of rare earth ions in solids. Fundamentals of Fiber Lasers and Fiber Amplifiers, 7-26.

15) Kesavulu, C. R., Kim, H. J., Lee, S. W., Kaewkhao, J., Wantana, N., Kothan, S., \& Kaewjaeng, S. (2016). Influence of $\mathrm{Er}^{3+}$ ion concentration on optical and photoluminescence properties of $\mathrm{Er}^{3+}$-doped gadolinium-calcium silica borate glasses. Journal of Alloys and Compounds, 683, 590-598.

16) Basavapoornima, C., Linganna, K., Kesavulu, C. R., Ju, S., Kim, B. H., Han, W. T., \& Jayasankar, C. K. (2017). Spectroscopic and pump power dependent upconversion studies of $\mathrm{Er}^{3+}$-doped lead phosphate glasses for photonic applications. Journal of Alloys and Compounds, 699, 959-968.

17) Rolli, R., Montagna, M., Chaussedent, S., Monteil, A., Tikhomirov, V. K., \& Ferrari, M. (2003). Erbium-doped tellurite glasses with high quantum efficiency and broadband stimulated emission cross section at $1.5 \mu \mathrm{m}$. Optical materials, 21(4), 743-748.

18) Soltani, I., Hraiech, S., Horchani-Naifer, K., Elhouichet, H., \& Férid, M. (2015). Effect of silver nanoparticles on spectroscopic properties of $\mathrm{Er}^{3+}$ doped phosphate glass. Optical Materials, 46, 454-460.

19) Judd, B. R. (1962). Optical absorption intensities of rare-earth ions. Physical review, 127(3), 750 .

20) Ofelt, G. S. (1962). Intensities of crystal spectra of rare-earth ions. The journal of chemical physics, 37(3), 511-520.

21) Baki, S. O., Tan, L. S., Kan, C. S., Kamari, H. M., Noor, A. S. M., \& Mahdi, M. A. (2013). Structural and optical properties of $\mathrm{Er}^{3+}-\mathrm{Yb}^{3+}$ codoped multicomposition $\mathrm{TeO}_{2^{-}}$ $\mathrm{ZnO}-\mathrm{PbO}-\mathrm{TiO}_{2}-\mathrm{Na}_{2} \mathrm{O}$ glass. Journal of non-crystalline solids, 362, 156-161.

22) Hamza, A. M., Halimah, M. K., Muhammad, F. D., \& Chan, K. T. (2019). Physical properties, ligand field and Judd-Ofelt intensity parameters of bio-silicate borotellurite glass system doped with erbium oxide. Journal of Luminescence, 207, 497-506. 
23) Yusoff, N. M., \& Sahar, M. R. (2015). Effect of silver nanoparticles incorporated with samarium-doped magnesium tellurite glasses. Physica B: Condensed Matter, 456, 191196.

24) Kothari, K. (2014). The Role of Molecular Mobility and Hydrogen Bonding Interactions on the Physical Stability of Amorphous Pharmaceuticals.

25) Hassan, M. A. (2013). Effect of halides addition on the ligand field of chromium in alkali borate glasses. Journal of alloys and compounds, 574, 391-397.

26) Al-Azzawi, A. (2007). International System of Units (SI). In Photonics: Principles and Practices (pp. 861-862). CRC Press.

27) Schubert, E. F. (2006). Light-Emitting Diodes (2006). E. Fred Schubert.

28) Johnson Jr, C. S. (2017). Science for the curious photographer: an introduction to the science of photography. Taylor \& Francis.

29) Vishwakarma, A. K., Jha, K., Jayasimhadri, M., Rao, A. S., Jang, K., Sivaiah, B., \& Haranath, D. (2015). Red light emitting $\mathrm{BaNb}_{2} \mathrm{O}_{6}: \mathrm{Eu}^{3+}$ phosphor for solid state lighting applications. Journal of Alloys and Compounds, 622, 97-101.

30) Nor, A. H. B. M. (2017). Optical properties of zinc borotellurite glass systems doped with dysprosium oxide and dysprosium oxide nanoparticles.

31) Vijayakumar, M., \& Marimuthu, K. (2015). Structural and luminescence properties of $\mathrm{Dy}^{3+}$ doped oxyfluoro-borophosphate glasses for lasing materials and white LEDs. Journal of Alloys and Compounds, 629, 230-241.

32) Mishra, L., Sharma, A., Vishwakarma, A. K., Jha, K., Jayasimhadri, M., Ratnam, B. V., ... \& Sinha, R. K. (2016). White light emission and color tunability of dysprosium doped barium silicate glasses. Journal of luminescence, 169, 121-127.

33) Mercola, J. (2008). Dark deception: Discover the truths about the benefits of sunlight exposure. Thomas Nelson Inc.

34) Sickler, D., \& Dean, S. E. (2010). The Keys to Color: A Decorator's Handbook for Coloring Paints, Plasters and Glazes. The Keys to Color.

35) Khan, T. Q., Bodrogi, P., Vinh, Q. T., \& Winkler, H. (Eds.). (2015). LED lighting: Technology and perception. John Wiley \& Sons.

36) McCamy, C. S. (1992). Correlated color temperature as an explicit function of chromaticity coordinates. Color Research \& Application, 17(2), 142-144.

37) Fang, M., Tan, X., Cao, X., Zhang, L., Liu, P., \& Jiang, Z. (2007). Impurity induced formation of $\mathrm{Sn}^{2+}$ ions in $\mathrm{SnO}_{2}$ and the photoluminescence property. Journal of Physics D: Applied Physics, 40(24), 7648.

38) Mahraz, Z. A. S., Sahar, M. R., Ghoshal, S. K., Dousti, M. R., \& Amjad, R. J. (2013). Silver nanoparticles enhanced luminescence of $\mathrm{Er}^{3+}$ ions in boro-tellurite glasses. Materials Letters, 112, 136-138.

39) Mahraz, Z. A. S., Sahar, M. R., \& Ghoshal, S. K. (2015). Enhanced luminescence from silver nanoparticles integrated $\mathrm{Er}^{3+}$-doped boro-tellurite glasses: Impact of annealing temperature. Journal of Alloys and Compounds, 649, 1102-1109.

40) Mahraz, Z. A. S., Sahar, M. R., \& Ghoshal, S. K. (2016). Impact of annealing time on silver nanoparticles growth assisted spectral features of erbium-zinc-boro-tellurite glass. Journal of Luminescence, 180, 1-7.

41) Dousti, M. R., Poirier, G. Y., Amjad, R. J., \& de Camargo, A. S. (2016). Luminescence quenching versus enhancement in $\mathrm{WO}_{3}-\mathrm{NaPO}_{3}$ glasses doped with trivalent rare earth ions and containing silver nanoparticles. Optical Materials, 60, 331-340. 
42) Jamalaiah, B. C., Kumar, J. S., Babu, A. M., Suhasini, T., \& Moorthy, L. R. (2009). Photoluminescence properties of $\mathrm{Sm} 3+$ in LBTAF glasses. Journal of luminescence, 129(4), 363-369.

43) Jaba, N., Mansour, H. B., Kanoun, A., Brenier, A., \& Champagnon, B. (2009). Spectral broadening and luminescence quenching of $1.53 \mu \mathrm{m}$ emission in Er3+-doped zinc tellurite glass. Journal of luminescence, 129(3), 270-276.

44) Hamza, A. M., Halimah, M. K., Muhammad, F. D., \& Chan, K. T. (2019). Physical properties, ligand field and Judd-Ofelt intensity parameters of bio-silicate borotellurite glass system doped with erbium oxide. Journal of Luminescence, 207, 497-506.

45) Ravi, O., Dhoble, S. J., Ramesh, B., Devarajulu, G., Reddy, C. M., Linganna, K., ... \& Raju, B. D. P. (2015). NIR fluorescence spectroscopic investigations of $\mathrm{Er}^{3+}$-ions doped borate based tellurium calcium zinc niobium oxide glasses. Journal of Luminescence, 164, 154-159.

46) Soltani, I., Hraiech, S., Horchani-Naifer, K., Elhouichet, H., \& Férid, M. (2015). Effect of silver nanoparticles on spectroscopic properties of $\mathrm{Er}^{3+}$ doped phosphate glass. Optical Materials, 46, 454-460.

47) Choi, Y. G., Kim, K. H., \& Heo, J. (1999). Spectroscopic properties of and energy transfer in $\mathrm{PbO}-\mathrm{Bi}_{2} \mathrm{O}_{3}-\mathrm{Ga}_{2} \mathrm{O}_{3}$ glass doped with $\mathrm{Er}_{2} \mathrm{O}_{3}$. Journal of the American Ceramic Society, 82(10), 2762-2768.

48) Jin, Z., Nie, Q., Xu, T., Dai, S., Shen, X., \& Zhang, X. (2007). Optical transitions and upconversion luminescence of $\mathrm{Er}^{3+} / \mathrm{Yb}^{3+}$ codoped lead-zinc-tellurite oxide glass. Materials chemistry and physics, 104(1), 62-67.

49) Rivera-López, F., Babu, P., Jyothi, L., Rodríguez-Mendoza, U. R., Martín, I. R., Jayasankar, C. K., \& Lavín, V. (2012). $\mathrm{Er}^{3+}-\mathrm{Yb}^{3+}$ codoped phosphate glasses used for an efficient $1.5 \mu \mathrm{m}$ broadband gain medium. Optical Materials, 34(8), 1235-1240.

50) Zhang, L., Peng, M., Dong, G., \& Qiu, J. (2012). An investigation of the optical properties of $\mathrm{Tb}^{3+}$-doped phosphate glasses for green fiber laser. Optical Materials, 34(7), 1202-1207.

51) Ter-Mikirtychev, V. (2014). Fundamentals of fiber lasers and fiber amplifiers.

52) Bilir, G., Kaya, A., Cinkaya, H., \& Eryürek, G. (2016). Spectroscopic investigation of zinc tellurite glasses doped with $\mathrm{Yb}^{3+}$ and $\mathrm{Er}^{3+}$ ions. Spectrochimica Acta Part A: Molecular and Biomolecular Spectroscopy, 165, 183-190.

53) Chen, R., Tian, Y., Li, B., Wang, F., Jing, X., Zhang, J., \& Xu, S. (2015). $2 \mu \mathrm{m}$ fluorescence of $\mathrm{Ho}^{3+}: 5 \mathrm{I} 7 \rightarrow 5 \mathrm{I} 8$ transition sensitized $\mathrm{by}^{3+}$ in tellurite germanate glasses. Optical Materials, 49, 116-122.

54) Balda, R., Lacha, L. M., Fernández, J., Arriandiaga, M. A., Fernández-Navarro, J. M., \& Muñoz-Martín, D. (2008). Spectroscopic properties of the $1.4 \mu \mathrm{m}$ emission of $\mathrm{Tm}^{3+}$ ions in $\mathrm{TeO}_{2}-\mathrm{WO}_{3}-\mathrm{PbO}$ glasses. Optics express, 16(16), 11836-11846.

55) Jlassi, I., Elhouichet, H., Hraiech, S., \& Ferid, M. (2012). Effect of heat treatment on the structural and optical properties of tellurite glasses doped erbium. Journal of luminescence, 132(3), 832-840.

56) Moustafa, S. Y., Sahar, M. R., \& Ghoshal, S. K. (2017). Spectroscopic attributes of $\mathrm{Er}^{3+}$ ions in antimony phosphate glass incorporated with Ag nanoparticles: Judd-Ofelt analysis. Journal of Alloys and Compounds, 712, 781-794. 
57) Fares, H., Jlassi, I., Hraiech, S., Elhouichet, H., \& Férid, M. (2014). Radiative parameters of $\mathrm{Nd}^{+}$-doped titanium and tungsten modified tellurite glasses for $1.06 \mu \mathrm{m}$ laser materials. Journal of Quantitative Spectroscopy and Radiative Transfer, 147, 224-232.

58) Mawlud, S. Q., Ameena, M. M., Sahar, M. R., Mahraz, Z. A. S., \& Ahmed, K. F. (2017, September). Thermal stability and Judd-Ofelt analysis of optical properties of $\mathrm{Sm}^{3+}$ doped sodium tellurite glasses. In AIP Conference Proceedings (Vol. 1888, No. 1, p. 020032). AIP Publishing LLC.

59) Mahraz, Z. A. S., Sahar, M. R., \& Ghoshal, S. K. (2017). Reduction of non-radiative decay rates in boro-tellurite glass via silver nanoparticles assisted surface plasmon impingement: Judd Ofelt analysis. Journal of Luminescence, 190, 335-343.

60) Yin, D., Qi, Y., Peng, S., Zheng, S., Chen, F., Yang, G., ... \& Zhou, Y. (2014). $\mathrm{Er}^{3+} / \mathrm{Tm}^{3+}$ codoped tellurite glass for blue upconversion-Structure, thermal stability and spectroscopic properties. Journal of luminescence, 146, 141-149.

61) Kothari, K. (2014). The Role of Molecular Mobility and Hydrogen Bonding Interactions on the Physical Stability of Amorphous Pharmaceuticals.

62) Jayasimhadri, M., Jang, K., Lee, H. S., Chen, B., Yi, S. S., \& Jeong, J. H. (2009). White light generation from $\mathrm{Dy}^{3+}$-doped $\mathrm{ZnO}-\mathrm{B}_{2} \mathrm{O}_{3}-\mathrm{P}_{2} \mathrm{O}_{5}$ glasses. Journal of Applied Physics, 106(1), 013105.

63) De Araújo, C. B., \& Kassab, L. R. P. (2016). Enhanced photoluminescence and planar waveguide of rare-earth doped germanium oxide glasses with metallic nanoparticles. In Glass Nanocomposites (pp. 131-144). William Andrew Publishing.

64) Maurya, S. K., Tiwari, S. P., Kumar, A., \& Kumar, K. (2018). Plasmonic enhancement of upconversion emission in $\mathrm{Ag} @ \mathrm{NaYF} 4: \mathrm{Er}^{3+} / \mathrm{Yb}^{3+}$ phosphor. Journal of Rare Earths, 36(9), 903-910.

65) Soares, M. R. N., Soares, M. J., Fernandes, A. J. S., Rino, L., Costa, F. M., \& Monteiro, T. (2011). YSZ: Dy ${ }^{3+}$ single crystal white emitter. Journal of Materials Chemistry, 21(39), 15262-15265.

66) Vijayakumar, R., Nagaraj, R., Suthanthirakumar, P., Karthikeyan, P., \& Marimuthu, K. (2018). Silver (Ag) nanoparticles enhanced luminescence properties of $\mathrm{Dy}^{3+}$ ions in borotellurite glasses for white light applications. Spectrochimica Acta Part A: Molecular and Biomolecular Spectroscopy, 204, 537-547.

67) Patwari, D. R., \& Eraiah, B. (2018). Luminescence properties of erbium doped sodium barium borate glass with silver nanoparticles. In Iop Conf Ser Mater Sci Eng (Vol. 310, pp. 012056-012063).

68) Cai, J., Wei, X., Hu, F., Cao, Z., Zhao, L., Chen, Y., \& Yin, M. (2016). Up-conversion luminescence and optical thermometry properties of transparent glass ceramics containing $\mathrm{CaF}_{2}: \mathrm{Yb}^{3+} / \mathrm{Er}^{3+}$ nanocrystals. Ceramics International, 42(12), 13990-13995.

69) Reddy, P. R. S., Reddy, T. S., Madhu, V., Gogia, A. K., \& Rao, K. V. (2015). Behavior of E-glass composite laminates under ballistic impact. Materials \& Design, 84, 79-86.

70) Pavani, K., Kumar, J. S., \& Moorthy, L. R. (2014). Luminescence properties of singlephase $\mathrm{SrMg} 2 \mathrm{La} 2 \mathrm{~W} 2 \mathrm{O} 12$ : $\mathrm{Tb} 3+, \mathrm{Sm} 3+, \mathrm{Tm} 3+$ phosphor for multicolor-and white lightemitting LEDs. Materials Research Express, 1(1), 016201.

71) Pascuta, P., \& Culea, E. (2008). FTIR spectroscopic study of some bismuth germanate glasses containing gadolinium ions. Materials Letters, 62(25), 4127-4129.

72) Wang, J. S., Vogel, E. M., \& Snitzer, E. (1994). Tellurite glass: a new candidate for fiber devices. Optical materials, 3(3), 187-203. 
73) Eevon, C., Halimah, M. K., Zakaria, A., Azurahanim, C. A. C., Azlan, M. N., \& Faznny, M. F. (2016). Linear and nonlinear optical properties of $\mathrm{Gd}^{3+}$ doped zinc borotellurite glasses for all-optical switching applications. Results in physics, 6, 761-766.

74) Muhammad Noorazlan, A., Mohamed Kamari, H., Zulkefly, S. S., \& Mohamad, D. W. (2013). Effect of erbium nanoparticles on optical properties of zinc borotellurite glass system. Journal of Nanomaterials, 2013.

75) Halimah, M. K., Nazrin, S. N., \& Muhammad, F. D. (2019). Influence of silver oxide on structural, physical, elastic and optical properties of zinc tellurite glass system for optical application. Chalcogenide Letters, 16(8).

76) Oo, H. M., Mohamed-Kamari, H., \& Wan-Yusoff, W. M. D. (2012). Optical properties of bismuth tellurite based glass. International journal of molecular sciences, 13(4), 46234631.

77) Fares, H., Jlassi, I., Elhouichet, H., \& Férid, M. (2014). Investigations of thermal, structural and optical properties of tellurite glass with $\mathrm{WO}_{3}$ adding. Journal of noncrystalline solids, 396, 1-7.

78) Saddeek, Y. B., Shaaban, K. H. S., Aly, K. A., Farag, R. S., \& Uosif, M. A. M. (2015). Studying effect of $\mathrm{SiO}_{2}$ on elastic properties of glasses based on environmental tailings using a nondestructive ultrasonic method. Int. J. New. Hor. Phys, 2(2), 53-57. 